\title{
Progress in organic-inorganic hybrid halide perovskite single crystal: growth techniques and applications
}

\author{
Jie Ding and Qingfeng Yan*
}

\begin{abstract}
As a new generation of solution-processable optoelectronic materials, organic-inorganic hybrid halide perovskites have attracted a great deal of interest due to their high and balanced carrier mobility, long carrier diffusion length and large light absorption coefficient. These materials have demonstrated wide applications in solar cell, light-emitting diode, laser, photodetector, catalysis and other fields. Comparing with their polycrystalline film counterpart, perovskite single crystals have low trap density and no grain boundaries and thus are anticipated to possess much better optoelectronic performances. Herein, we review the key progress in the development of organic-inorganic halide perovskite single crystals. Particularly, the crystal growth techniques and applications of these advanced materials are highlighted.
\end{abstract}

Keywords: organic-inorganic hybrid halide, perovskite, single crystal

\section{INTRODUCTION}

The past several years have witnessed the booming development of organic-inorganic hybrid halide perovskite. Perovskites are a family of materials with chemical formula $\mathrm{ABX}_{3}$. In a typical perovskite crystal structure, $\mathrm{B}$ occupies the center of an octahedral $\left[\mathrm{BX}_{6}\right]^{4-}$ cluster, while $\mathrm{A}$ is 12 -fold cuboctahedral coordinated with $\mathrm{X}$ anions. For organic-inorganic hybrid halide perovskite, A stands for cation like methylammonium $\left(\mathrm{MA}^{+}\right)$or formamidinium $\left(\mathrm{FA}^{+}\right)$, B stands for metal ion like $\mathrm{Pb}^{2+}$ or $\mathrm{Sn}^{2+}$, and $\mathrm{X}$ stands for halide, usually $\mathrm{Cl}^{-}, \mathrm{Br}^{-}, \mathrm{I}^{-}$. Although the initial studies of these materials can date back to the 1970s [1,2], their complex behavior, extraordinary properties, and chemical and physical subtleties have been revealed only recently. Benefiting from the unique organic-inorganic hybrid crystal structure and the diversity of the A-site, B-site and $\mathrm{X}$ ions, perovskite materials possess a lot of intriguing characteristics such as high light absorption coefficient [3], tunable direct bandgaps [4], low exciton binding energy [5], long charge carrier diffusion lengths [6,7], high ambipolar charge mobilities [8,9], and extended charge carrier lifetime [10]. Most of these characteristics meet the materials requirement of high-efficiency solar cells very well $[11,12]$. Thus, perovskite solar cells have made impressive progress in just a few years with maximum power conversion efficiencies (PCEs) evolving from 3.8\% [13] in 2009 to a certified 22.1\% [14] in 2016. Besides solar cell, organic-inorganic hybrid halide perovskites have been found many other applications, such as light-emitting diode [15], laser [16], photodetector [17], catalysis [18], thermoelectricity [19], making them hot stars in materials science.

There are two main forms of organic-inorganic hybrid halide perovskites, i.e., polycrystalline films and single crystals. Currently, perovskite thin films have been under intensive investigation and most reported applications have focused on polycrystalline thin films. Accordingly, a lot of recent reviews regarding the progress in perovskites concentrate on their polycrystalline film form [20-35]. Although the study of perovskite single crystals is just in its early stage, it is highly desirable to investigate fundamentally intrinsic properties of perovskites due to their low trap density and absence of grain boundaries. More importantly, recent studies have shown that perovskite single crystals possess much better opotoelectrical properties than their polycrystalline film counterparts. Shi et al. [36] observed low trap-state density on the order of $10^{9}$ to $10^{10}$ $\mathrm{cm}^{-3}$ and long charge carrier diffusion lengths exceeding 10 micrometers in $\mathrm{MAPbX}_{3}$ single crystals. Dong et al. [37] reported that the diffusion lengths in $\mathrm{MAPbI}_{3}$ single

Department of Chemistry, Tsinghua University, Beijing 100084, China

* Corresponding author (email: yanqf@mail.tsinghua.edu.cn) 
crystals could exceed $175 \mu \mathrm{m}$ under 1 sun illumination and exceed $3 \mathrm{~mm}$ under weak light for both electrons and holes, which far exceeds the value measured for polycrystalline $\mathrm{MAPbI}_{3}$ films (typically smaller than $1 \mu \mathrm{m}$ ). The long carrier diffusion length allows the photogenerated charge carriers to be completely extracted from perovskite single crystals with an active layer thickness much larger than thin-film analogues, which is very desirable for both photovoltaic and photodetection applications. These intriguing findings have triggered the increasing interest in organic-inorganic hybrid halide perovskite single crystals. In the past several years, a variety of organic-inorganic hybrid halide perovskite single crystals have been demonstrated. Herein, we review the key advancements in growth techniques and applications.

\section{GROWTH OF BULK SINGLE CRYSTAL}

The synthesis and crystal growth of organic-inorganic halide perovskite single crystals can date back to 1978, when Weber firstly reported the crystal structures of $\mathrm{MAPbX}_{3}$ and $\mathrm{MASnX}_{3}[38,39]$. In 2013, Stoumpos et al. [40] studied the characteristics of tin and lead iodide perovskites with organic cations using millimeter single crystals, in agreement with the results of Baikie et al. [41]. The pioneer work on the growth of centimeter-sized (10 $\mathrm{mm} \times 10 \mathrm{~mm} \times 8 \mathrm{~mm}) \mathrm{MAPbI}_{3}$ bulk single crystal was done by Dang et al. [42] in 2014. From then on, more and more techniques have been adopted to grow organic-inorganic hybrid halide perovskite single crystals and even fully inorganic halide perovskite single crystals. These methods can be divided into four categories, i.e., solution temperature-lowering (STL) method, inverse temperature crystallization (ITC) method, anti-solvent vapor-assisted crystallization (AVC) method, and melt crystallization method, as shown in Scheme 1.

\section{STL method}

STL method is a modification of the original Weber's method and comes to be a classic way to gain large-size organic-inorganic hybrid halide perovskite single crystals [43]. Usually, millimeter small crystals are firstly synthesized, followed by seeded growth of large-size bulk single crystals. Dependent on the different fixed positions of the seed crystals, bottom seeded solution growth (BSSG) and top seeded solution growth (TSSG) methods have been developed. Tao's [42] group adopted the BSSG method to grow $\mathrm{MAPbI}_{3}$ bulk single crystals. The small seeded crystal was fixed to the middle of a designed tray. The tray with the seed crystal was rotated by the electric motor. Then, the saturated solution was slowly cooled down from $65^{\circ} \mathrm{C}$ to $40^{\circ} \mathrm{C}$. The $\mathrm{MAPbI}_{3}$ single crystal with dimensions of 10 $\mathrm{mm} \times 10 \mathrm{~mm} \times 8 \mathrm{~mm}$ was attained as shown in Fig. 1a. Our group also utilized a seed crystal fixed to a platinum wire to obtain bulk single crystals with the size of $12 \mathrm{~mm}$ $\times 12 \mathrm{~mm} \times 7 \mathrm{~mm}$ via the BSSG method after lowering the temperature of the growth solution from $100^{\circ} \mathrm{C}$ to $57^{\circ} \mathrm{C}$, as shown in Fig. 1b [44]. These solution-grown $\mathrm{MAPbI}_{3}$ bulk single crystals typically exhibited two natural facets $\{100\}$ and $\{112\}$, as shown in Fig. 1a, b.

Huang's [37] group reported the growth of $\mathrm{MAPbI}_{3}$ bulk single crystals by TSSG method. During the crystal growth, the seed crystal was fixed to a silicon substrate on the top of

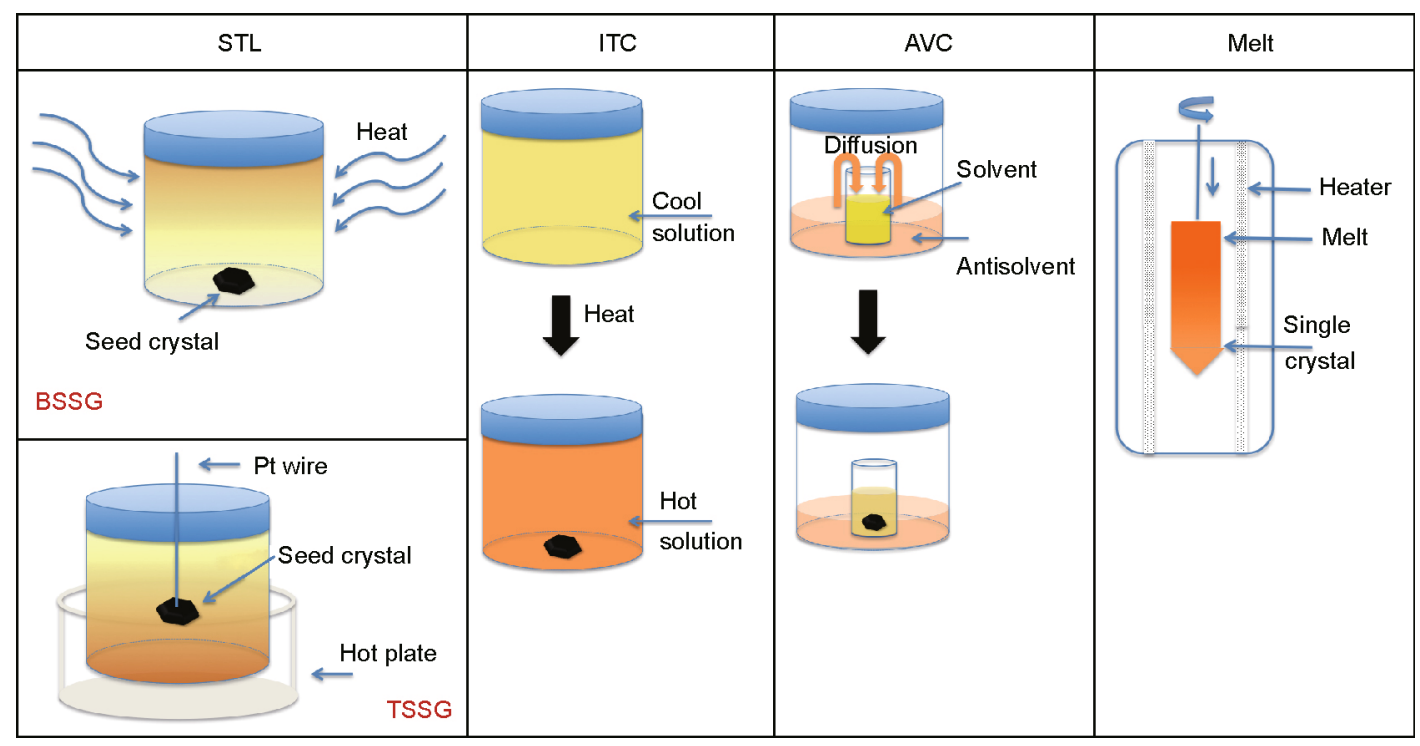

Scheme 1 Illustration of different growth methods. 
a

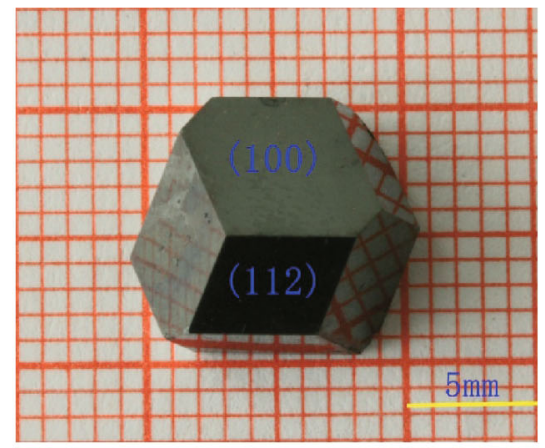

d

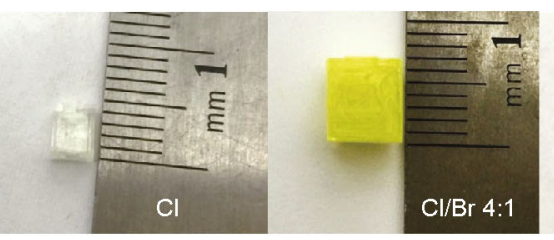

e

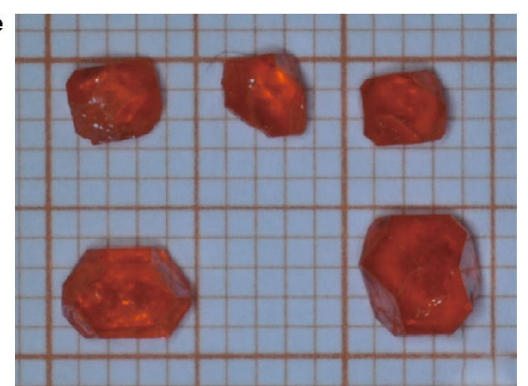

h

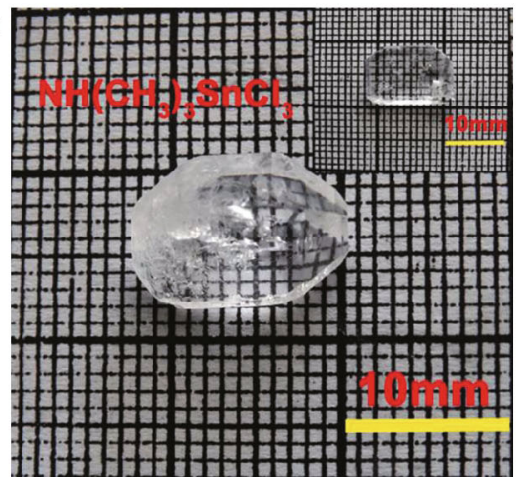

b
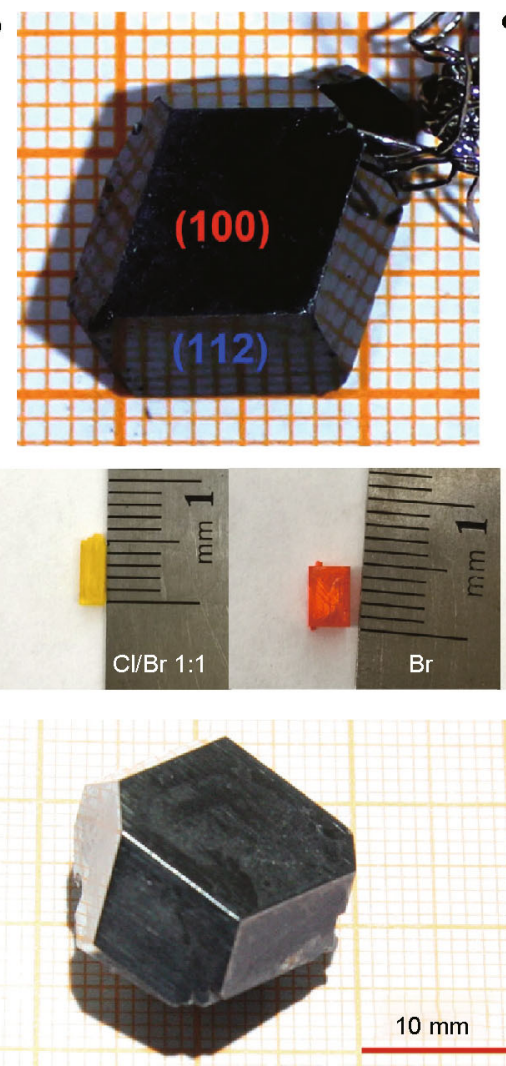

c
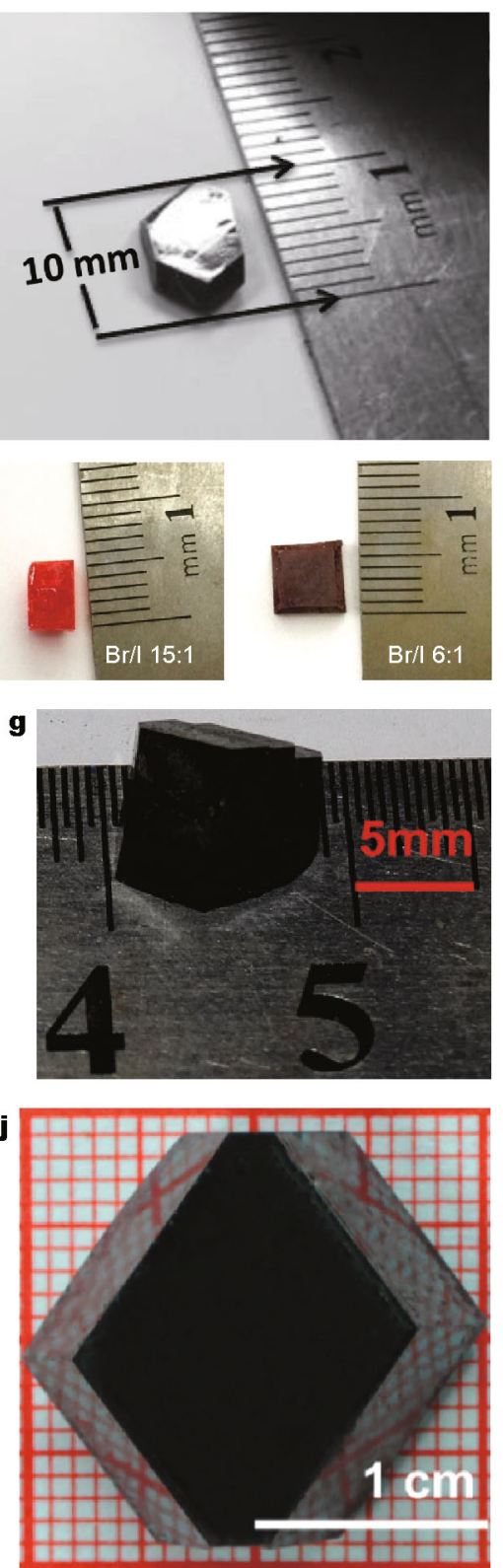

Figure 1 Photograph of different perovskite single crystals grown by STL method. (a-c) $\mathrm{MAPbI}_{3}$ single crystals. Reprinted with permission from [42]. Copyright 2015, the Royal Society of Chemisty; [44] Copyright 2015, Springer; [37] Copyright 2015, the American Association for the Advancement of Science, respectively. (d) Mixed-halide perovskite single crystals with different $\mathrm{Cl} / \mathrm{Br}$ and $\mathrm{Br} / \mathrm{I}$ precursor ratios. Reprinted with permission from [45], Copyright 2015, Springer. (e) $\mathrm{MAPbBr}_{3}$ single crystals. Reprinted with permission from [46], Copyright 2015, Elsevier. (f) $\mathrm{CH}_{3} \mathrm{NH}_{3} \mathrm{SnI}_{3}$ single crystal and (g) $\mathrm{CH}\left(\mathrm{NH}_{2}\right)_{2} \mathrm{SnI}_{3}$ single crystal. Reprinted with permission from [47], Copyright 2016, Wiley. (h) $\left.\mathrm{NH}_{(\mathrm{CH}}\right)_{3} \mathrm{SnCl}{ }_{3}$ single $\mathrm{crystal}$ and (i) $\mathrm{NH}\left(\mathrm{CH}_{3}\right)_{3} \mathrm{SnBr}_{3}$ single crystal. Reprinted with permission from [48], Copyright 2016, the American Chemical Society. (j) MAPbI $\mathrm{M}_{3}$ single crystal with a rapid STL method. Reprinted with permission from [49], Copyright 2016, the American Chemical Society.

the growth precursor solution. Bulk $\mathrm{MAPbI}_{3}$ single crystals of $10 \mathrm{~mm} \times 3.3 \mathrm{~mm}$ in size, as shown in Fig. 1c, were harvested via the dissolution of small seed crystals in the bottom due to the temperature gradient between the bottom and top of the solution that induced super saturation. The $\mathrm{MAPbI}_{3}$ single crystals presented much lower trap- state density of about $10^{10} \mathrm{~cm}^{-3}$ and longer carrier diffusion length (exceeding $175 \mu \mathrm{m}$ ) than those of $\mathrm{MAPbI}_{3}$ polycrystalline films $\left(\sim 10^{15} \mathrm{~cm}^{-3}\right.$ and $\sim 100 \mathrm{~nm}$, respectively). Huang's group also demonstrated the growth of single- and mixed-halide perovskite single crystals with different $\mathrm{Cl} / \mathrm{Br}$ and $\mathrm{Br} / \mathrm{I}$ precursor ratios [45]. The precursor solution was 
prepared by mixing methylamine, single or mixed haloid acid with different halide ratios, and lead(II) acetate to form a super saturated aqueous solution at $100^{\circ} \mathrm{C}$. The single crystals were attained from the precursor solution by gradually lowering the temperature. Photographs of typical single-halide and mixed-halide perovskite single crystals with different $\mathrm{Cl} / \mathrm{Br}$ and $\mathrm{Br} / \mathrm{I}$ precursor ratios are presented in Fig. 1d. As can be seen, for the $\mathrm{MAPbBr}_{3-x} \mathrm{Cl}_{x}$ single crystals, the colour gradually changed from transparent to yellow and finally to orange with increasing $\mathrm{Br} /(\mathrm{Cl}+\mathrm{Br}) \mathrm{mo}-$ lar ratio from 0 to 1 in the precursor solution. For the $\mathrm{MAPbI}_{3-x} \mathrm{Br}_{x}$ single crystals, the colour gradually changed from orange to red with increasing $\mathrm{I} /(\mathrm{I}+\mathrm{Br})$ molar ratio. Using similar STL method, Su et al. [46] grew large $\mathrm{MAPbI}_{3}$ single crystals with size up to $1 \mathrm{~cm}$ and $\mathrm{MAPbBr}_{3}$ single crystals with size around $5 \mathrm{~mm}$ (Fig. 1e). Recently, bulk $\mathrm{CH}_{3} \mathrm{NH}_{3} \mathrm{SnI}_{3}$ and $\mathrm{CH}\left(\mathrm{NH}_{2}\right)_{2} \mathrm{SnI}_{3}$ single crystals have also been grown via the TSSG method by Tao's [47] group for the first time (Fig. 1f, g). $\mathrm{NH}\left(\mathrm{CH}_{3}\right)_{3} \mathrm{SnX}_{3}(\mathrm{X}=\mathrm{Cl}, \mathrm{Br})$ bulk single crystals were also harvested with the same TSSG method (Fig. 1h, i) [48].

Although STL methods provide a simple, convenient and applicable approach for the growth of large-sized $\mathrm{MAPbX}_{3}$ single crystals, such methods are time-consuming [49]. It typically costs 2-4 weeks to obtain one-centimeter sized crystals. Most recently, we demonstrated that large single crystals of perovskite $\mathrm{MAPbI}_{3}$ could be grown rapidly from chlorine-containing solutions. Within only 5 days, $\mathrm{MAPbI}_{3}$ single crystal as large as $20 \mathrm{~mm} \times 18 \mathrm{~mm} \times 6 \mathrm{~mm}$ was harvested (Fig. 1j). As a most important index to evaluate the crystalline quality, the full width at half-maximum (FWHM) in the high-resolution X-ray rocking curve (HR$\mathrm{XRC}$ ) of the as-grown $\mathrm{MAPbI}_{3}$ single crystal was measured as 20 arcsec, which was comparable to some familiar semiconductor bulk crystals, such as SiC (27 arcsec), AlN (72 arcsec), and $\mathrm{GaN}$ (90 arcsec). The unparalleled crystalline quality delivered a low trap-state density of down to $7.6 \times$ $10^{8} \mathrm{~cm}^{-3}$, high carrier mobility of $167 \pm 35 \mathrm{~cm}^{2} \mathrm{~V}^{-1} \mathrm{~s}^{-1}$, and long transient photovoltaic carrier lifetime of $449 \pm 76 \mu \mathrm{s}$ [49]. The improvement in the crystalline quality, together with the rapid growth rate and excellent carrier transport property, provides state-of-the-art single crystalline hybrid perovskite materials for high-performance optoelectronic devices.

\section{ITC method}

ITC method, initially proposed by Bakr et al. [50,51], is based on the unnormal solubility of organic-inorganic hybrid halide perovskite in specific organic solvents. In this method, crystallization is induced by the inverse solubility dependent on temperature in some organic solvents and the overall growth occurs within several hours, which is much faster than that in STL method. Therefore, ITC method has been widely used to grow large-size organic-inorganic hybrid halide perovskite single crystals [52-55].

During ITC, the growth procedure is a balance of dissolution and precipitation. At low temperature, molecules of perovskite are bound in the complexes by the solvent molecules completely. In other words, the unbound molecules do not reach saturation. While the bonding energy decreases with the increase of temperature, more free perovskite molecules concentrate in solution. $\mathrm{Nu}$ cleation appears at some point when the solution comes to supersaturation, followed by crystal growth. Choosing appropriate solvent is the key to grow a good single crystal. For example, for $\mathrm{MAPbI}_{3}, \mathrm{MAPbBr}_{3}$ and $\mathrm{MAPbCl}_{3}$, the optimal solvent would be gamma-butyrolactone (GBL), $N, N$-dimethylformamide (DMF), and dimethylsulfoxide (DMSO), respectively.

The rapid ITC method was firstly used for the synthesis of $\mathrm{MAPbI}_{3}$ and $\mathrm{MAPbBr}_{3}$ single crystals (Fig. 2a, b) [50,56]. Later, Zhao and coworkers [57] found that this method was also feasible to grow mixed halide perovskite $\left(\mathrm{CH}_{3} \mathrm{NH}_{3}\right) \mathrm{Pb}\left(\mathrm{Br}_{1-x} \mathrm{Cl}_{x}\right)_{3}$ single crystals (Fig. 2c).

It is well accepted that $\mathrm{FAPbX}_{3}$ hold better stability in comparison with $\mathrm{MAPbX}_{3}$. Bakr's [51] group found that the retrograde behavior and ITC were not limited to $\mathrm{MAPbX}_{3}$ perovskites but could be generalized to $\mathrm{FAPbX}_{3}$ by proper solvent selection. For ITC of $\mathrm{FAPbI}_{3}, 0.8 \mathrm{~mol} \mathrm{~L}^{-1}$ GBL solution was used to increase the onset of crystallization temperature to $115^{\circ} \mathrm{C}$. Crack- and grain boundary-free black $\mathrm{FAPbI}_{3}$ single crystals could be successfully grown in $3 \mathrm{~h}$ (Fig. 2d). For ITC of $\mathrm{FAPbBr}_{3}, 1 \mathrm{~mol} \mathrm{~L}^{-1}$ solution in 1:1 $(v / v)$ DMF:GBL was used with the crystallization onset at $55^{\circ} \mathrm{C}$ to grow crack-free $\mathrm{FAPbBr}_{3}$ crystals (Fig. 2e). Yang's [55] group also reported a modified ITC method to grow 5 mm sized $\mathrm{FAPbI}_{3}$ single crystal. They used a cooling solution method to first grow the $\mathrm{FAPbI}_{3}$ seed crystal, followed by placing the seed crystals in an inverse temperature crystallization precursor to obtain larger crystals.

For commercial applications, larger crystals with dimension in inches are needed. By combining ITC method and repeated seeded growth, Liu's [58] group has grown super large-sized $\mathrm{MAPbX}_{3}$ single crystals (Fig. 3a-d). The largest crystal produced was as large as $71 \mathrm{~mm} \times 54 \mathrm{~mm} \times 39 \mathrm{~mm}$ in dimension, which is the first time to report this type of perovskite crystals with dimensions exceeding half an inch. 
a

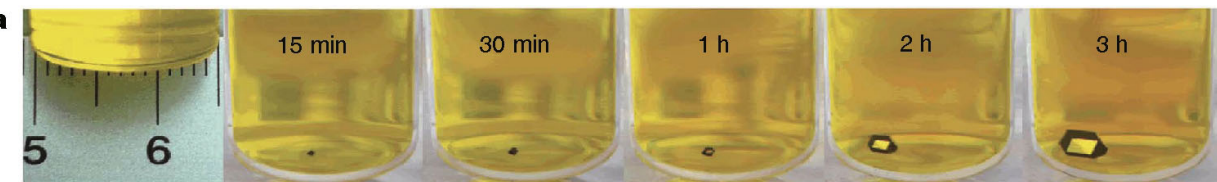

b

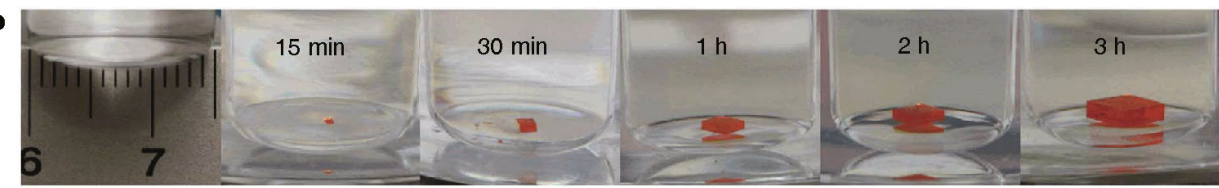

c
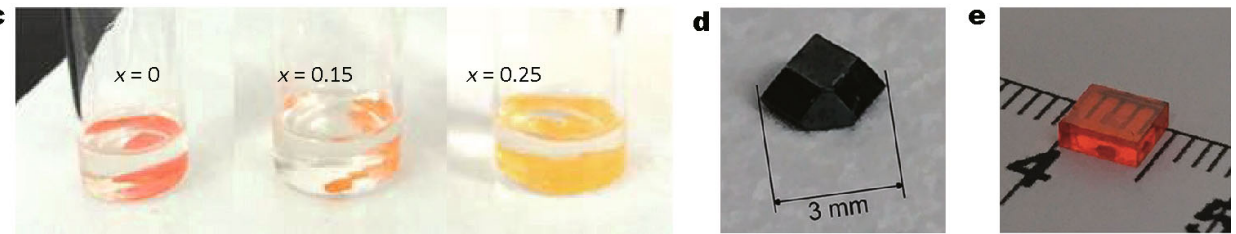

Figure 2 (a, b) $\mathrm{MAPbI}_{3}$ and $\mathrm{MAPbBr}_{3}$ crystal growth at different time intervals with an ITC method. Reprinted with permission from [50], Copyright 2015, Springer. (c) Single crystals of $\mathrm{CH}_{3} \mathrm{NH}_{3} \mathrm{~Pb}\left(\mathrm{Br}_{1-x} \mathrm{Cl}_{x}\right)_{3}$. Reprinted with permission from [57], Copyright 2015, the Royal Society of Chemisty. (d) $\mathrm{FAPbI}_{3}$ crystal and (e) $\mathrm{FAPbBr}_{3}$ crystal. Reprinted with permission from [51], Copyright 2016, the Royal Society of Chemisty.

a

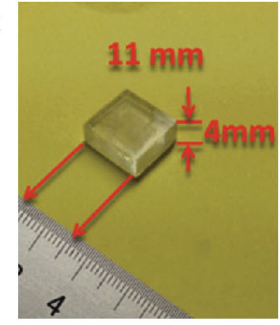

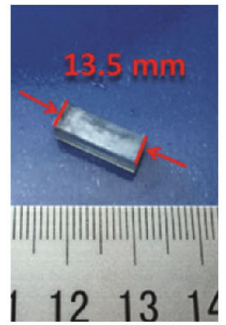
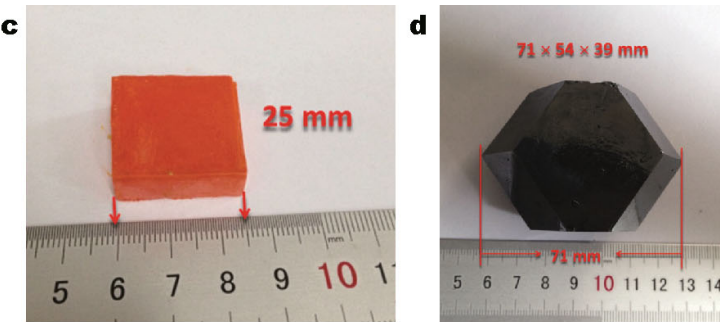

e

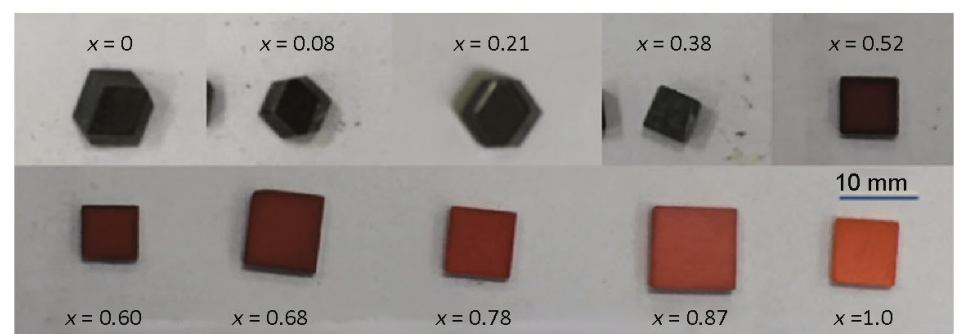

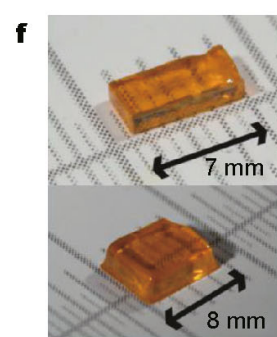

Figure 3 Photographs taken from the as-grown $\mathrm{CH}_{3} \mathrm{NH}_{3} \mathrm{PbX}_{3}$ crystals. (a, b) $\mathrm{X}=\mathrm{Cl}$; (c) $\mathrm{X}=\mathrm{Br}$; (d) $\mathrm{X}=\mathrm{I}$. Reprinted with permission from [58], Copyright 2015, Wiley. (e) Photographs of $\mathrm{MAPb}\left(\mathrm{Br}_{x} \mathrm{I}_{1-x}\right)_{3}$ single crystals. Reprinted with permission from [60], Copyright 2016, the Royal Society of Chemisty. (f) Photographs of the obtained $\mathrm{CsPbBr}_{3}$ single crystals. Reprinted with permission from [61], Copyright 2016, the American Chemical Society.

According to the X-ray $2 \theta$ measurement, the $\mathrm{MAPbI}_{3}$ crystal shows a FWHM of $0.3718^{\circ}$ for the (200) diffraction peak, indicating that it is a single crystal with respectable crystalline quality. Electric characterization showed that the hole trap density is $2.6 \times 10^{10} \mathrm{~cm}^{-3}$ for $\mathrm{MAPbBr}_{3}$ and $1.8 \times 10^{9} \mathrm{~cm}^{-3}$ for $\mathrm{MAPbI}_{3}$. The electron trap densities are determined for $\mathrm{MAPbBr}_{3}$ and $\mathrm{MAPbI}_{3}$ to be $1.1 \times 10^{11} \mathrm{~cm}^{-3}$ and $4.8 \times 10^{10} \mathrm{~cm}^{-3}$ respectively. Such low trap density and high carrier mobility indicate that the wafer-sized large single-crystalline $\mathrm{MAPbX}_{3}(\mathrm{X}=\mathrm{Cl}, \mathrm{Br}, \mathrm{I})$ is a promising material for high-performance optoelectronic devices. Re- cently, the same group demonstrated that large-sized (20 $\mathrm{mm}) \mathrm{FAPbI}_{3}$ single crystals could also be attained by using the similar technique [59]. Most recently, they reported the growth of mixed halide perovskites $\operatorname{MAPb}\left(\mathrm{Br}_{x} \mathrm{I}_{1-x}\right)_{3}(x$ $=0-1$ ) single crystals as shown in Fig. 3e [60]. Although it is well known that an appropriate solvent is of paramount importance for growth of halide perovskite single crystals, e.g., GBL works best for $\mathrm{MAPbI}_{3}, \mathrm{DMSO}$ for $\mathrm{MAPbCl}_{3}$ and $\mathrm{DMF}$ for $\mathrm{MAPbBr}_{3}$, it is still challenging to prepare mixed halide perovskite single crystals using a single solvent for both precursor materials. By using individually optimized 
precursor solutions of $\mathrm{MAPbBr}_{3}$ in $\mathrm{DMF}$ and $\mathrm{MAPbI}_{3}$ in GBL, they grew a series of 10 dual-halide perovskite $\operatorname{MAPb}\left(\mathrm{Br}_{x} \mathrm{I}_{1-x}\right)_{3}(x=0-1)$ single crystals. As expected, the band gap could be continuously modulated over a broad range from 1.53 to $2.24 \mathrm{eV}$ by changing the $\mathrm{Br}$ content in the single crystals.

Apart from organic-inorganic hybrid halide perovskites, it was found that fully inorganic halide perovskite single crystals could also be grown by using ITC method. Such all-inorganic analogs may overcome the known issues of chemical instability of organic-inorganic hybrid perovskites. Dirin et al. [61] reported a simple and fast route to solution growth of $\mathrm{CsPBr}_{3}$ single crystals using ITC method, under ambient atmosphere and using low-cost precursors. The growth of $\mathrm{CsPbBr}_{3}$ was carried out in DMSO. Specifically, a $\mathrm{CsBr}: \mathrm{PbBr}_{2}$ solution in a mixture of DMSO with cyclohexanol and DMF, was heated to $90^{\circ} \mathrm{C}$ in a vial, leading to the formation of 1-3 nuclei. Subsequent heating to $110^{\circ} \mathrm{C}$ led to further growth without additional nucleation. $\mathrm{A} \sim 8 \mathrm{~mm}$ long, flat, orange-colored $\mathrm{CsPbBr}_{3}$ single crystal can be attained within several hours (Fig. 3f). Similarly, Rakita et al. [62] reported the growth of $\mathrm{CsPbBr}$ single crystals by using a modified ITC method.

\section{AVC method}

AVC method takes advantage of perovskite's different solubility in different solvents to achieve crystallization. Unlike the STL and ITC methods, the AVC method is not subject to temperature. Hence, it avoids the temperature-dependent phase transitions in $\mathrm{MAPbX}_{3}$. In addition, it is more independent without considering the external factors like temperature field problem.

Bakr's [36] group first reported the successful growth of sizable and high-quality $\mathrm{MAPbX}_{3}$ crystals by using the AVC method. During crystal growth, an appropriate anti-solvent is slowly diffused into a solution containing the target crystal precursors, leading to the nucleation and growth of crystals. To grow $\mathrm{MAPbBr}_{3}$ single crystal, $\mathrm{PbBr}_{2}$ and $\mathrm{MABr}$ (1/1 by molar, $0.2 \mathrm{~mol} \mathrm{~L}^{-1}$ ) were dissolved in DMF first. Along with the slow diffusion of the vapor of the anti-solvent dichloromethane (DCM) into the solution, crystallization of $\mathrm{MAPbBr}_{3}$ could be observed (Fig. 4a). The same technique was also feasible for crystallizing $\mathrm{MAPbI}_{3}$ single crystals as shown in Fig. 4b. In this case, $\mathrm{PbI}_{2}$ and MAI ( $1 / 3$ by molar, $\mathrm{PbI}_{2}$ : $0.5 \mathrm{~mol} \mathrm{~L}^{-1}$ ) were dissolved in GBL, while DCM was used as an anti-solvent. These highquality single crystals exhibited exceptionally low trap-state densities of $\sim 10^{9}-10^{10} \mathrm{~cm}^{-3}$ and incredibly long charge carrier diffusion lengths exceeding $10 \mu \mathrm{m}$. In another report,
Yang et al. [63] used DMF as a solvent to prepare $\mathrm{PbBr}_{2}$ and $\mathrm{CH}_{3} \mathrm{NH}_{3} \mathrm{Br}$ mixture solution. Then, toluene was used as an anti-solvent to induce crystallization of $\mathrm{MAPbBr}_{3}$. Similarly, Zhou et al. [64] reported $\mathrm{MAPbI}_{3}$ single crystal grown by AVC method and analyzed the growth mechanism. They used diethyl ether as an anti-solvent and $\mathrm{HI}$ as a good solvent. Owing to the coordination between $\mathrm{PbI}_{2}$ and $\mathrm{HI}, \mathrm{PbI}_{2}$ powder dissolved in $\mathrm{HI}$ solution easily. Then it transformed to $\mathrm{H}_{x} \mathrm{PbI}_{2+x} \cdot x \mathrm{H}_{2} \mathrm{O}$ as an intermediate product proved by XRD analysis. With the slow introduction of diethyl ether, the final $\mathrm{MAPbI}_{3}$ single crystal was observed.

The AVC method can also apply to the growth of fully inorganic halide perovskite. Rakita et al. [62] reported a modified AVC method to grow $\mathrm{Cs} \mathrm{PbBr}_{3}$ single crystals. A precursor $\left(\mathrm{PbBr}_{2}\right.$ and $\left.\mathrm{CsBr}\right)$ DMSO solution was first titrated with one of the following anti-solvents: acetonitrile $(\mathrm{MeCN})$ or methanol $(\mathrm{MeOH})$. The presaturation step was to prevent precipitation of the undesired $\mathrm{Cs}_{4} \mathrm{PbBr}_{6}$ alongside to the desired $\mathrm{CsPbBr}_{3}$. Millimeter-sized crystals were grown without crystal-seeding and could provide a $100 \%$ yield of $\mathrm{CsPBBr}_{3}$ perovskite crystals (Fig. 5).

\section{Melt crystallization method}

Melt crystallization techniques such as Czochralski method
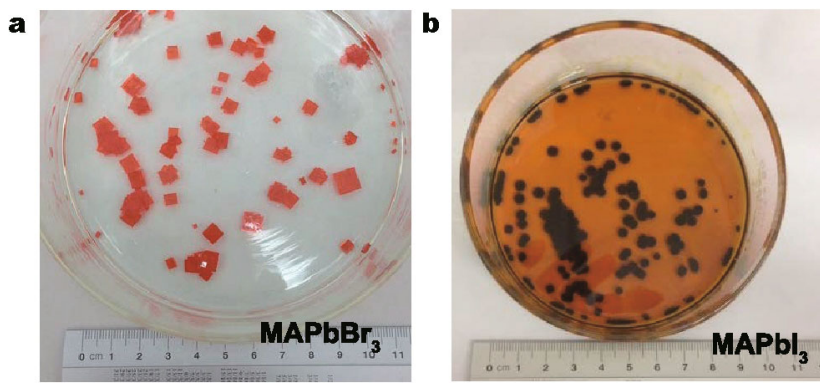

Figure 4 (a) $\mathrm{MAPbBr}_{3}$ and (b) $\mathrm{MAPbI}_{3}$ single crystals. Reprinted with permission from [36], Copyright 2015, the American Association for the Advancement of Science.

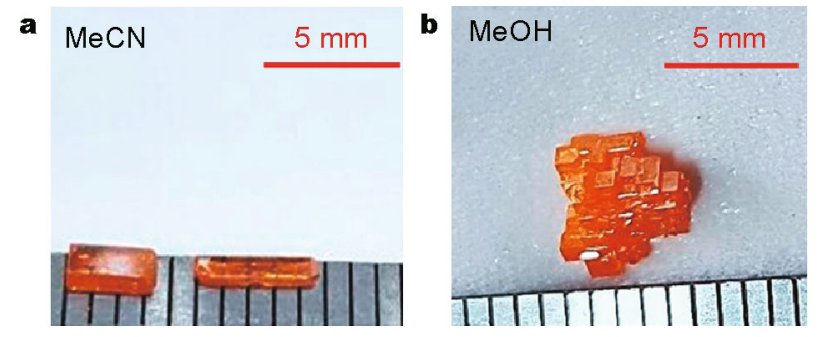

Figure $5 \mathrm{CsPbBr}_{3}$ crystals grown by a modified AVC method. (a) Grown from $\mathrm{MeCN}$ saturated solution on a $50^{\circ} \mathrm{C}$ hot plate. (b) Grown from $\mathrm{MeOH}$ saturated solutions at room temperature. Reprinted with permission from [62], Copyright 2016, the American Chemical Society. 
and Bridgman method have been widely employed to grow large-size industrially important functional crystals. However, due to the high vapour pressure and chemical instability of organic compounds around their melting temperatures, there have been no reports about the crystal growth of inorganic-organic hybrid perovskite materials using these techniques. Nevertheless, melt crystallization techniques should pave the way for fully inorganic halide perovskite materials with a definite melting point. Kobayashi et al. [65] first reported the growth of $\mathrm{CsPbCl}_{3}$ single crystals with Bridgmann technique using raw powders of $\mathrm{PbCl}_{2}$ and $\mathrm{CsCl}$ of $99.99 \%$ purity sealed in vacuum in a quartz crucible. Recently, Stoumpos et al. [66] reported the growth of $\mathrm{CsPbBr}_{3}$ single crystals. $\mathrm{CsPbBr}_{3}$ powders were finely ground with a mortar and pestle and placed in a fused silica tube so that the height of the solid in the tube was approximately half the length of the tube. The tube was carefully brought to a $10^{-4}$ mbar vacuum, and flame-sealed. The ampoule was attached to a clock mechanism and was slowly lowered into a 3-zone vertical tube furnace with a temperature gradient of $10^{\circ} \mathrm{C} \mathrm{mm}$. The dropping speed was varied between 3 and $30 \mathrm{~mm} \mathrm{~h}^{-1}$. Orange, transparent crystals were obtained. The pictures in Fig. 6 show the single-crystal specimens of $\mathrm{CsPbBr}_{3}$ cut from the grown crystal ingots.

\section{GROWTH OF SINGLE CRYSTAL FILM}

Although the hybrid perovskites have been extensively studied, it is worth noting that the perovskite absorber layers in perovskite solar cells, even the best one reached a certified $22.1 \%$ PCE, are based on microcrystallines. This could be limited by the lack of a facile and effective way to

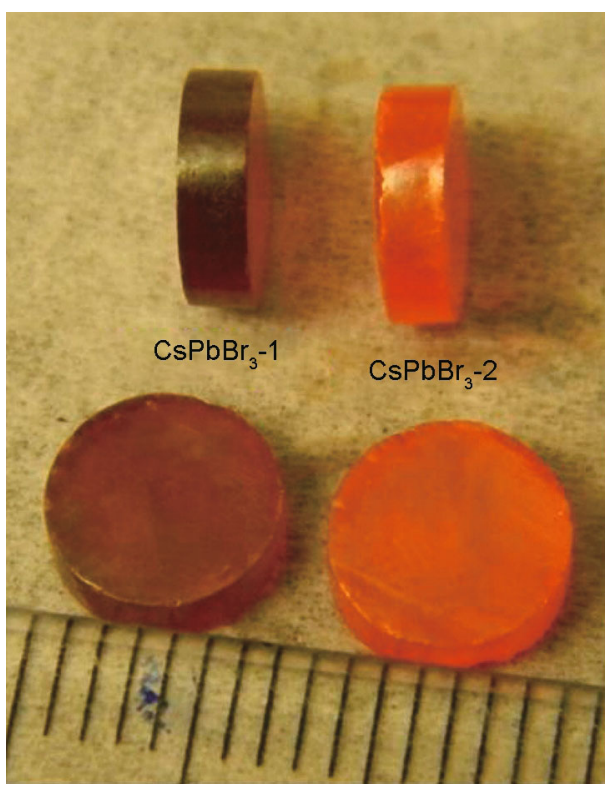

Figure 6 Photograph of the $\mathrm{CsPbBr}_{3}-1$ and $\mathrm{CsPbBr}_{3}-2$ single-crystal with melt crystallization method. Reprinted with permission from [66], Copyright 2013, the American Chemical Society.

fabricate large single-crystalline thin films. At the same time, although perovskite bulk single crystals showing much higher carrier mobility and longer diffusion length and carrier lifetime have advanced significantly, application of these bulk single crystals in devices may cause degradation of device performance due to the increase of charge recombination as the active layer thickness is too thick. In this regard, the fabrication of perovskite single-crystalline thin films is highly desirable and intriguing to boost device performance.

Table 1 A summary of different bulk single crystal growth methods and properties of as grown crystals

\begin{tabular}{|c|c|c|c|c|c|}
\hline \multirow{2}{*}{ Growth method } & \multirow{2}{*}{ Single crystal } & \multicolumn{3}{|c|}{ Properties } & \multirow{2}{*}{ Ref. } \\
\hline & & Size $(\mathrm{mm})$ & Carrier mobility $\left(\mathrm{cm}^{2} \mathrm{~V}^{-1} \mathrm{~s}^{-1}\right)$ & Trap state density $\left(\mathrm{cm}^{-3}\right)$ & \\
\hline \multirow{4}{*}{ STL method } & $\mathrm{MAPbI}_{3}$ & $10 \times 10 \times 8$ & \multirow{4}{*}{$\begin{array}{l}105 \pm 35 \\
167 \pm 35\end{array}$} & \multirow{4}{*}{$\begin{array}{c}10^{10} \\
7.6 \times 10^{8}\end{array}$} & {$[40]$} \\
\hline & $\mathrm{MAPbI}_{3}$ & $12 \times 12 \times 7(2-4$ weeks $)$ & & & {$[42]$} \\
\hline & $\mathrm{MAPbI}_{3}$ & $10 \times 3.3$ & & & [35] \\
\hline & $\mathrm{MAPbI}_{3}$ & $20 \times 18 \times 6(5$ days $)$ & & & {$[47]$} \\
\hline \multirow{5}{*}{ ITC method } & $\mathrm{MAPbI}_{3}$ & $\sim 5(3 \mathrm{~h})$ & 67.2 & \multirow{5}{*}{$\begin{array}{l}1.4 \times 10^{10} \\
1.8 \times 10^{9} \\
2.6 \times 10^{10}\end{array}$} & {$[50]$} \\
\hline & $\mathrm{MAPbI}_{3}$ & $71 \times 54 \times 39$ & 34 & & {$[58]$} \\
\hline & $\mathrm{MAPbCl}_{3}$ & (3 days to grow $7 \mathrm{~mm}$ ) & 179 & & {$[58]$} \\
\hline & $\mathrm{MAPbBr}_{3}$ & $11 \times 11 \times 4$ & $\begin{array}{c}4.36 \\
\sim 2 \times 10^{-4} \mathrm{~cm}^{2} \mathrm{~V}^{-1}\end{array}$ & & {$[58]$} \\
\hline & $\mathrm{CsPbBr}{ }_{3}$ & $\sim 8 \mathrm{~mm}$ (several hours) & (Mobility-lifetime) & & {$[61]$} \\
\hline AVC method & $\mathrm{MAPbI}_{3}$ & $\sim 1$ & 2.5 & $\sim 10^{9}-10^{10}$ & {$[34]$} \\
\hline $\begin{array}{l}\text { Melt crystallization } \\
\text { method }\end{array}$ & $\mathrm{CsPbBr}_{3}$ & $\sim 7$ diameter & $\begin{array}{c}1000 \\
1.7 \times 10^{-3} \mathrm{~cm}^{2} \mathrm{~V}^{-1} \\
\text { (Mobility-lifetime) }\end{array}$ & & {$[66]$} \\
\hline
\end{tabular}


Bakr's [67] group first reported the successful growth and characterization of hybrid perovskite $\mathrm{MAPbBr}_{3}$ monocrystalline films on substrates by using a cavitation-triggered asymmetrical crystallization method. As shown in the photographic image (Fig. 7a), as well as the cross-sectional scanning electron microscopy (SEM) image (Fig. 7b), these semitransparent films are homogeneous and free of grain boundaries, with thicknesses varying from one up to several tens of micrometers, and lateral dimensions ranging from hundreds of microns to three millimeters. Later, Liu's [68] group reported a smart way to grow ultrathin single crystal perovskite wafers based on the ITC method as schematically shown in Fig. 7c. They built an ultrathin geometry-defined dynamic-flow reaction system to control the thickness of crystal. The $\mathrm{MAPbI}_{3}$ wafer thickness could be controlled to as thin as about $150 \mu \mathrm{m}$. The X-ray diffraction (XRD) and rocking-curve measurements showed that the obtained $\mathrm{MAPbI}_{3}$ wafers had high crystallinity. Besides, the trap state density of wafer was measured as low as $6 \times$ $10^{8} \mathrm{~cm}^{-3}$.

Recently, Chen et al. [69] demonstrated a facile space-confined solution-processed strategy to on-substrate grow various hybrid perovskite single-crystalline thin films (SCTFs) in a size of submillimeter with adjustable thicknesses from nano to micrometers (Fig. 7d). The prepared perovskite SCTFs exhibited excellent air stability and comparable quality to bulk single crystals with a trap density of $4.8 \times 10^{10} \mathrm{~cm}^{-3}$, carrier mobility of 15.7 $\mathrm{cm}^{2} \mathrm{~V}^{-1} \mathrm{~s}^{-1}$, and carrier lifetime of $84 \mu \mathrm{s}$. Furthermore, it was found that the perovskite SCTF growth did not require lattice match with the substrate. It could be directly grown on a variety of flat substrates including silicon wafer (with or without dielectric film), flexible plastic substrate such as polyethylene terephthalate (PET), glass, quartz, mica, indium tin oxide (ITO), fluorinated tin oxide (FTO), etc. This substrate-independent growth brought appealing potentials to on-chip fabricate perovskite devices for diverse applications, e.g., perovskite solar cells, optical devices, electronic devices, flexible devices, etc. More recently, an amazing large-area of $120 \mathrm{~cm}^{2} \mathrm{CH}_{3} \mathrm{NH}_{3} \mathrm{PbBr}_{3}$ perovskite crystal films with a steerable thickness of $0.1-0.8 \mathrm{~mm}$ have been successfully prepared via an ingenious space-limited ITC method by Rao et al. [70], as shown in Fig. 7e. The super-large-area $\mathrm{CH}_{3} \mathrm{NH}_{3} \mathrm{PbBr}_{3}$ crystal film presented
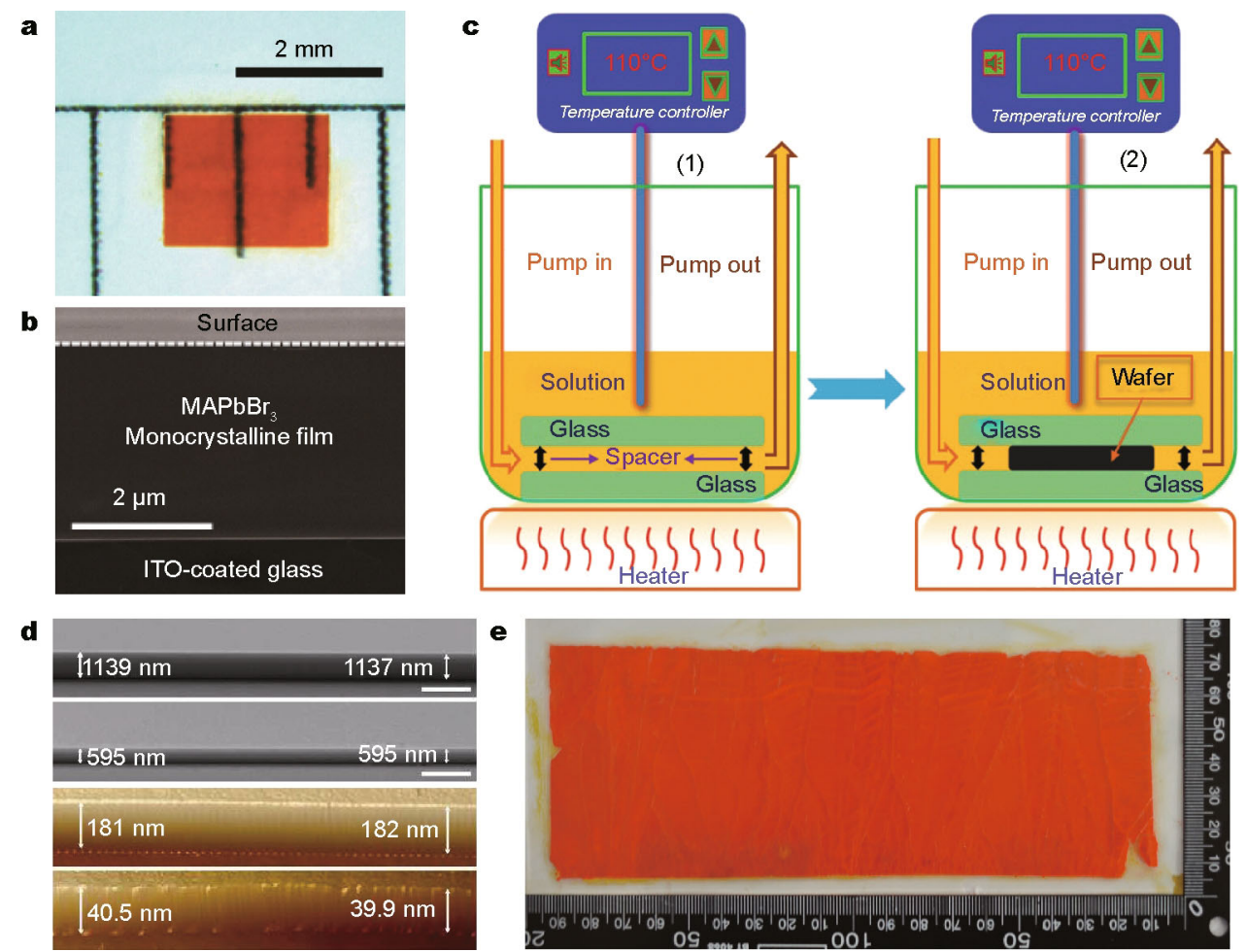

Figure 7 (a) Optical image and (b) cross-section SEM image of the MAPbBr 3 monocrystalline film. Reprinted with permission from [67], Copyright 2016, Wiley. (c) A schematic illustration for the ultrathin single crystal wafer preparation. Reprinted with permission from [68], Copyright 2016, Wiley. (d) Cross-section SEM images and atomic force microscopy (AFM) images of $\mathrm{MAPbBr}_{3}$ SCTFs with varied thicknesses. Reprinted with permission from [69], Copyright 2016, American Chemical Society. (e) The photograph of $\mathrm{CH}_{3} \mathrm{NH}_{3} \mathrm{PbBr}_{3}$ crystal films with a thickness of $0.4 \mathrm{~mm}$ and an area about 120 $\mathrm{cm}^{2}$. Reprinted with permission from [70], Copyright 2017, Wiley. 
excellent electron mobility of $40.7 \mathrm{~cm}^{2} \mathrm{~s}^{-1} \mathrm{~V}^{-1}$, low trap density of $8.80 \times 10^{10} \mathrm{~cm}^{-3}$, and long electron diffusion length of $6.4 \mu \mathrm{m}$.

\section{APPLICATIONS OF THE PEROVSKITE SINGLE CRYSTALS}

\section{Fundamental study of intrinsic properties of perovskites}

The emergence of large-size and high-quality organic-inorganic hybrid halide perovskite single crystals provides an ideal platform to investigate fundamentally intrinsic properties of perovskites due to their absence of grain boundaries and existence of low trap density. For example, in-situ investigation of the photophysics properties of a $\mathrm{CH}_{3} \mathrm{NH}_{3} \mathrm{PbBr}_{3}$ single crystal under dark and irradiation indicated that the illumination was able to rearrange the piezoresponse force microscopy (PFM) phase angles in bulk crystal and force them to become convergent. A large surface potential change of $200 \mathrm{mV}$ was also observed due to the accumulation of built-in potential fields in $\mathrm{CH}_{3} \mathrm{NH}_{3} \mathrm{PbBr}_{3}$ single crystal under light [71]. Fang et al. [72] studied the photophysics of $\mathrm{MAPbI}_{3}$ single crystal. By temperature-dependent steady-state and time-resolved photoluminescence test, the photoexcitation landscape was demonstrated. They attributed the long lifetime to the bond excitons, which had a triplet-state nature.

Yang et al. [73] found that bulk $\mathrm{CH}_{3} \mathrm{NH}_{3} \mathrm{PbI}_{3}$ single crystal support amplified spontaneous emission under two- and three-photon excitations over a range of operation temperature. Bakr's [53] group's study showed that $\mathrm{FAPbBr}_{3}$ crystals displayed a 5-fold longer carrier lifetime and 10-fold lower dark carrier concentration than those of $\mathrm{MAPbBr}_{3}$ single crystals. Long carrier diffusion lengths, $6.6 \mu \mathrm{m}$ for $\mathrm{FAPbI}_{3}$ and $19.0 \mu \mathrm{m}$ for $\mathrm{FAPbBr}_{3}$ single crystals, were detected, both of which were much longer than previously thought. Valverde-Chávez [74] studied the dynamics and efficiencies of free charge creation and charge carrier mobility of $\mathrm{MAPbI}_{3}$ single crystal with optical pump-multi-THz spectroscopy in the 4-125 meV range optical pulse. Fang's [75] group studied the photon recycling of $\mathrm{CH}_{3} \mathrm{NH}_{3} \mathrm{PbI}_{3}$ and $\mathrm{CH}_{3} \mathrm{NH}_{3} \mathrm{PbBr}_{3}$ single crystals and quantified the efficiency less than $0.5 \%$. Hence the photon recycling was not the origin of the long carrier diffusion length of perovskite single crystal. Recently, we reported the anisotropy of moisture erosion observed in $\mathrm{CH}_{3} \mathrm{NH}_{3} \mathrm{PbI}_{3}$ single crystals. When exposed to moisture, the (001) facet exhibited greater sensitivity to water molecules and showed a faster erosion rate compared to the (100) facet and (112) facet. Structural and chemical origins responsible for anisotropic moisture erosion were elucidated [76].

\section{Device applications}

Owing to their superior optoelectric properties, organic-inorganic hybrid halide perovskites single crystals have demonstrated a lot of device applications. Some representative applications are highlighted below.

\section{Photodetector}

Photodetectors can convert light signals into electrical signal. Hence, high sensitivity and fast speed photodetectors have a lot of applications like biological sensing, camera imaging, missile warning, and communications, etc. [77-80]. For a photodetector, responsivity $(R)$ and external quantum efficiency (EQE) are the two key parameters to describe the device performance. The responsivity can be defined as $R=I_{\mathrm{L}}-I_{\mathrm{D}} / P_{0} \times S$, where $I_{\mathrm{L}}$ is the light current, $I_{\mathrm{D}}$ is the dark current, $P_{0}$ is the irradiance power density and $S$ is the effective illuminated area. The $R$ stands for the photoelectric conversion efficiency. The EQE can be described as EQE $=R h c / e \lambda$, where $R$ is the responsivity, $h$ is Planck's constant, $c$ is the velocity of light, $e$ is the electron charge, and $\lambda$ is the wavelength of incident light. The EQE stands for the electrons generated divided by the incident photons.

For the first time, Lian et al. [44] reported a planar-type photodetector based on $\mathrm{MAPbI}_{3}$ perovskite single crystal as schematically shown in Fig. 8a. The single crystal photodetector showed better performance than its polycrystalline counterpart as shown in Fig. 8b, about $10^{2}$ times higher $R$ and EQE, and approximately $10^{3}$ times faster response speed. Fang et al. [45] reported highly narrowband photodetector based on a series of halide perovskite single crystals due to the strong surface-charge recombination-induced suppression of charge collection for shortwavelength excitation. By tuning the molar ratio of $\mathrm{Cl} / \mathrm{Br}$ precursor, perovskite with different band gap can be produced. The device showed an ultra-narrow EQE peak with an FWHM of $<20 \mathrm{~nm}$, and a detection limit down to 80 pW cm$~^{-2}$ as shown in Fig. 8c-e. Maculan et al. [52] reported an efficient visible-blind UV-photodetector based on ITC-grown $\mathrm{MAPbCl}_{3}$ single crystals. Fang et al. [81] combined a perovskite single crystal photodetector with a triboelectric nanogenerator to make the self-power device. Driven by the nanogenerator, the photodetector with a large responsivity of $196 \mathrm{~V}\left(\mathrm{~mW} \mathrm{~cm}^{-2}\right)^{-1}$ can work without external electric field. Ding et al. [82] reported a self-powered photodetector based on a $\mathrm{MAPbI}_{3}$ single crystal with 

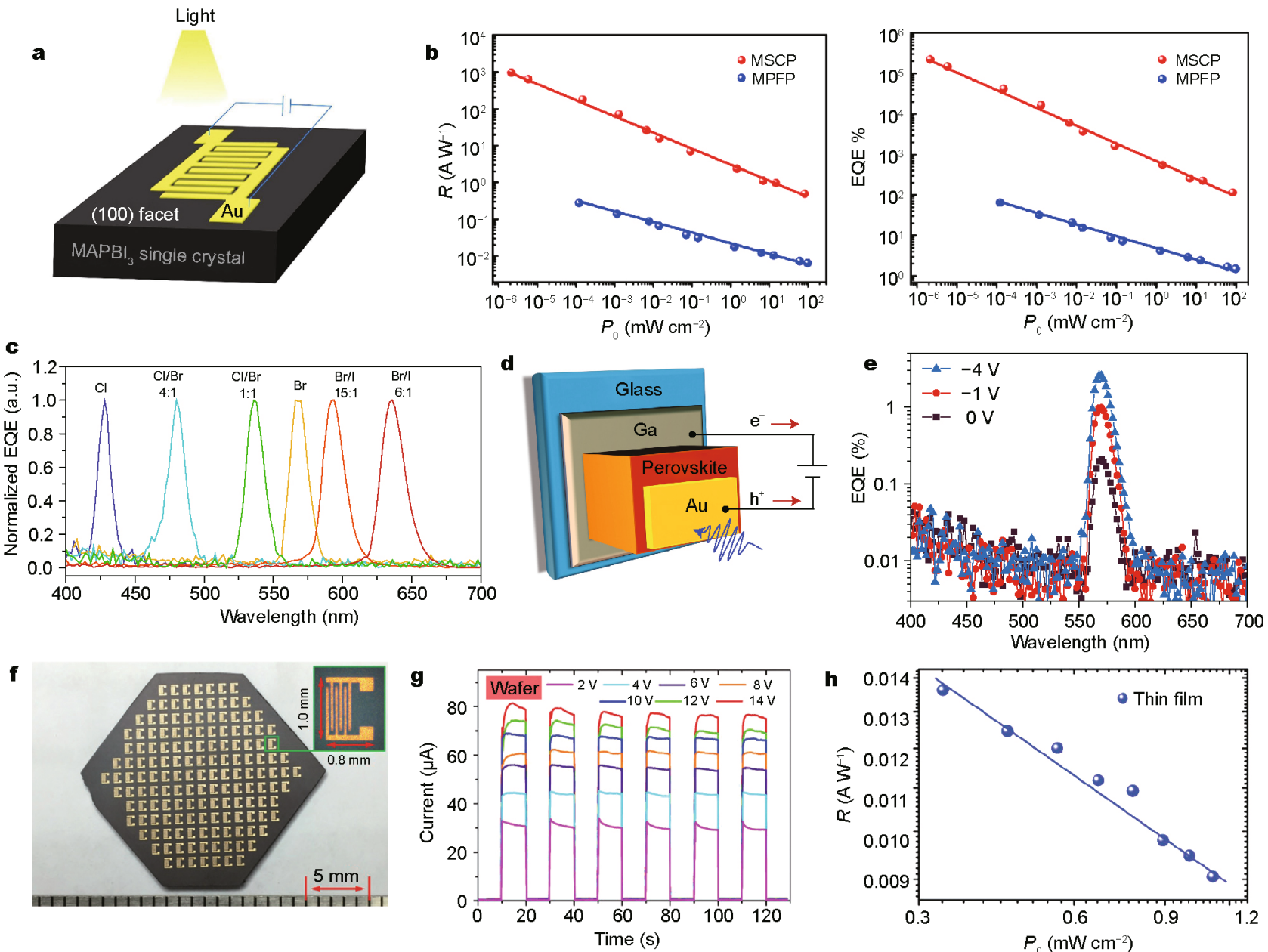

Figure 8 (a, b) Device structure and response of the $\mathrm{MAPbI}_{3}$ single crystal photodetector. Reprinted with permission from [44], Copyright 2015, Springer. (c) Normalized EQE spectra of different composite perovskite; (d, e) schematic of device structure and performance. Reprinted with permission from [45], Copyright 2015, Springer. (f-h) Mass production of photodetectors and their peroformance. Reprinted with permission from [59, 68], Copyright 2017, Wiley; Copyright 2016, Wiley.

$\mathrm{Au}-\mathrm{Al}$ asymmetric electrodes. The device showed a responsivity of $0.24 \mathrm{~A} \mathrm{~W}^{-1}$ at the lowest noticeable incident power density of $1 \times 10^{-8} \mathrm{~W} \mathrm{~cm}^{-2}$ and a fast response time of $71 \mu$ s under zero bias. Shaikh et al. [83] also prepared a self-biased photodetector with AVC-grown $\mathrm{MAPbBr}_{3}$ single crystals. They utilized Pt-Au electrods to make a Shottkey junction, which demonstrated a photodetectivity of $1.4 \times 10^{10}$ Jones at zero bias. Cao et al. [84] fabricated a self-powered photodetector based on core-shell $\mathrm{CH}_{3} \mathrm{NH}_{3} \mathrm{PbBr}_{3}$ single crystal heterojunction. The responsivity of photodetector was up to $11.5 \mathrm{~mA} \mathrm{~W}^{-1}$ under 450 $\mathrm{nm}$ irradiation at zero bias. By simply depositing 300 $\mathrm{nm}$ interdigital $\mathrm{Au}$ electrodes via vacuum evaporation method, Liu's group demonstrated the mass production of integrated photodetectors based on large-sized $\mathrm{FAPbI}_{3}$ and $\mathrm{MAPbI}_{3}$ perovskite single crystal wafer, as shown in Fig. 8f-h. More recently, the $120 \mathrm{~cm}^{2}$ large-area $\mathrm{CH}_{3} \mathrm{NH}_{3} \mathrm{PbBr}_{3}$ perovskite crystal film has been successfully applied to narrowband photodetectors, which enabled a broad linear response range of $10^{-4}-10^{2} \mathrm{~mW} \mathrm{~cm}^{-2}, 3 \mathrm{~dB}$ cutoff frequency $\left(f_{3 \mathrm{~dB}}\right)$ of $\sim 110 \mathrm{kHz}$, and high narrow response under low bias of $-1 \mathrm{~V}[70]$.

\section{Solar cell}

Based on the hybrid perovskite monocrystalline films grown by the cavitation-triggered asymmetrical crystallization method, Bakr's [67] group made the first explorative study on perovskite monocrystalline solar cells using two different device structures: $\mathrm{ITO}_{\mathrm{MAPbBr}} \mathrm{MA}_{3}$ $\mu \mathrm{m}) / \mathrm{Au}$ and $\mathrm{FTO} / \mathrm{TiO}_{2} / \mathrm{MAPbBr}_{3}(1 \mu \mathrm{m}) / \mathrm{Au}$. Dark and illuminated $J-V$ curves of these monocrystalline solar cells are shown in Fig. 9a, b, respectively. By utilizing a simple 

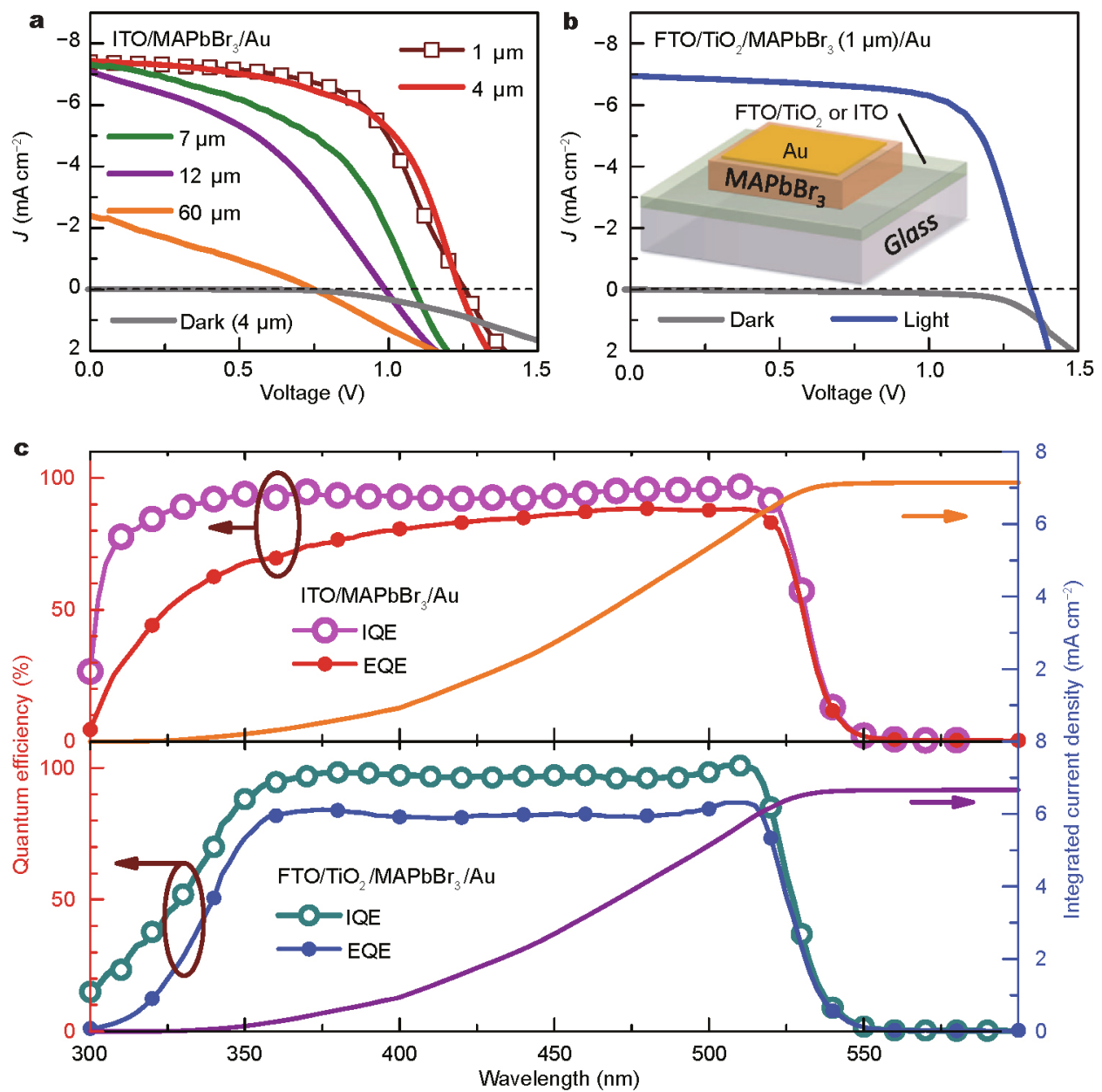

Figure $9 \mathrm{~J}$ - $V$ curves (a) ITO-based and (b) $\mathrm{FTO} / \mathrm{TiO}_{2}$-based monocrystalline solar cells, respectively. (c) The quantum efficiency curves and current density curves of devices. Reprinted with permission from [67], Copyright 2016, Wiley.

cell structure of ITO/MAPbBr $3(4 \mu \mathrm{m}) / \mathrm{Au}$, the internal quantum efficiency (IQE) was up to $100 \%$, and an ultra-stable PCE was $>5 \%$. Furthermore, the efficiency can be enhanced to $6.5 \%$ by employing a single $\mathrm{p}-\mathrm{n}$-junction-based architecture instead, which was better than the best HTL-free $\mathrm{MAPbBr}_{3}$ solar cells, as shown in Fig. 9c. These results provide direct proof for the superior optoelectronic properties of perovskite monocrystalline films in devices over their polycrystalline counterparts. With the millimeter sized bulk single crystal, it's hard to make a high efficiency solar cell. However, Dong et al. [85] fabricated lateral structure perovskite single crystal solar cells via piezoelectric poling. A highest PCE of 5.36\% can be reached at $170 \mathrm{~K}$ which yields an efficiency enhancement of 44 folds of the polycrystalline film.

High-energy ray detector

High-energy ray detector can convert high-energy rays such as X-ray and $\gamma$-ray photons to charges. It has been applied in the fields of security inspection, medical imaging, industrial material inspection, etc. [86-88]. For X-ray detection, the crystal layer collects $\mathrm{X}$-ray photons and charges are generated. Hence, charge carrier mobility and lifetime are very critical for a high sensitivity $\mathrm{X}$-ray detector. In addition, crystal's atomic constituents $Z$ play an important role for X-ray attenuation coefficient $\alpha\left(\alpha \propto Z^{4} / E^{3}\right.$, where $E$ is the $\mathrm{X}$-ray photon energy) [89].

Due to the excellent carrier transport properties of halide perovskites and high- $Z$ elements $\mathrm{Pb}, \mathrm{I}$, or $\mathrm{Br}$, perovskites have shown their great potential for X-ray detection [90]. Yakunin et al. [91] reported X-ray detection in $\mathrm{MAPbI}_{3}$ films first, exhibiting X-ray sensitivity of $25 \mu \mathrm{C} \mathrm{mGy}$ air $^{-1} \mathrm{~cm}^{-3}$ and responsivity of $1.9 \times 10^{4}$ carriers/photon. Náfrádi et al. [92] reported a mass attenuation coefficient of $14 \pm 1.2 \mathrm{~cm}^{2} \mathrm{~g}^{-1}$ and charge collection efficiency of $75 \pm 6 \%$ for unfiltered $X$-ray radiation in the $20-35$ 
keV range based on $\mathrm{MAPbI}_{3}$ bulk crystals, as shown in Fig. 10a, b. Both works show high dark currents, which limits the sensitivity of X-ray detection. Wei et al. [93] reported $\mathrm{X}$-ray detector based on bulk $\mathrm{MAPbBr}_{3}$ single crystal for the first time. By optimizing the device structure and a surface passivation, a detector with a charge collection efficiency of $33 \%-42 \%$ for UV-vis light, $16.4 \%$ for hard $\mathrm{X}$-ray photons at near zero bias could be attained, as shown in Fig. 10d-f. In addition, the sensitivity was up to 80 $\mu \mathrm{C} \mathrm{Gy} \mathrm{air}^{-1} \mathrm{~cm}^{-2}$.

Recently, a direct-conversion $\gamma$-ray detector was reported by Yakunin et al. [94]. They proved lead halide perovskites $\mathrm{MAPbI}_{3}, \mathrm{FAPbI}_{3}$ and I-treated $\mathrm{MAPbBr}_{3}$ can act as $\gamma$-raydetecting materials. Among them, device based on $\mathrm{FAPbI}_{3}$ single crystal exhibited the highest charge-carrier mobility-lifetime product and the lowest noise levels and dark currents, showing great potential for $\gamma$-ray detection.

\section{CONCLUSIONS AND OUTLOOK}

Organic-inorganic hybrid halide perovskites have emerged as promising solution-processable optoelectronic materials. In comparison with polycrystalline film, perovskite single crystals possess remarkably lower trap densities, higher charge mobilities, longer carrier diffusion lengths and better stability, thus receiving increasing attention. In this review, we outlined recent advancements of growth techniques and applications of organic-inorganic halide perovskites single crystals. Large-sized bulk single crystals are usually prepared by anti-solvent vapor-assisted crystallization, seed solution-growth method, cooling-induced crystallization and solvothermal growth methods. STL method, ITC method and AVC method have been classic and well-recognized techniques to grow large-sized organic-inorganic halide perovskites bulk single crystals, some of which even demonstrate their ability to grow fully inorganic halide perovskites single crystals. There are also successful examples of growth of $\mathrm{CsPbBr}_{3}$ and $\mathrm{CsPbCl}_{3}$ single crystals by using the melt crystallization technique. It should be noted that two-inch-sized organic-inorganic halide perovskites bulk single crystals have been demonstrated by using a repeated seed-assisted ITC method, showing an inviting vista of commercialization of these materials. Furthermore, the appearance of organic-inorganic halide perovskites single crystalline films may pave
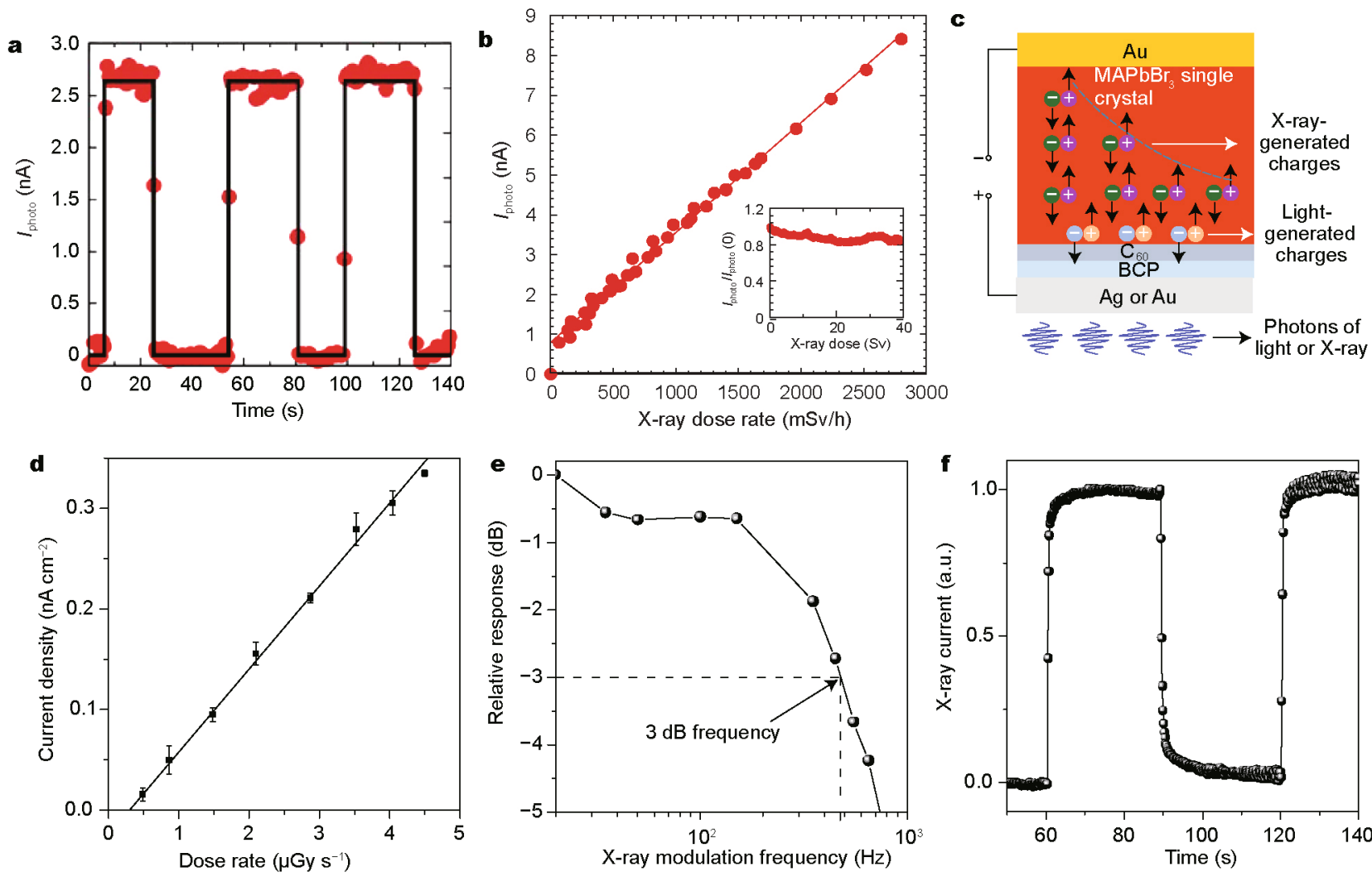

Figure 10 (a, b) X-ray detection performance of the $\mathrm{MAPbI}_{3}$ single-crystal devices. Reprinted with permission from [92], Copyright 2015, the American Chemical Society. (c) Structure illustration of single crystal radiation detector; (d-f) X-ray detection performance of the MAPbBr 3 single-crystal devices. Reprinted with permission from [93], Copyright 2016, Wiley. 
the way to the wide-spread applications.

On one hand, hybrid halide perovskites single crystals provide ideal platforms for fundamental studies due to the absence of grain boundaries, especially in the context of photophysics mechanism, stability, charge transportation, and charge recombination dynamics. On the other hand, hybrid halide perovskites single crystals provide a promising material choice for the fabrication of high-performance optoelectronic devices such as photodetectors, solar cells, high-energy ray detectors and so on. For the future work in this area, the preparation of large-sized, high-quality, thickness-controlled, orientation-controlled hybrid halide perovskites single crystals is still a big challenge. For example, ITC method demonstrates a rapid crystal growth approach, but degenerated crystalline quality especially the surface quality is usually observed due to solvent corrosion. Although several methods have been adopted to fabricate single crystalline films, the general applicabilities of these methods to organic-inorganic hybrid halide perovskites need to be further proved. Additionally, it should be noted that most of the demonstrated device applications of perovskites single crystals have focused on photodectors. Their application in solar cells, which is the most recognized application area for perovskites thin films, is still very limited. The reason lies that it is still hard to attain a perovskite single crystal with an appropriate thickness for classic solar cell structure. The potential of perovskite in solar cell has not been fully realized. It is believed that further advancement could be expected by developing device-oriented crystal growth techniques.

Received 12 March 2017; accepted 19 April 2017; published online 16 May 2017

1 Møller CK. A phase transition in cæsium plumbochloride. Nature, 1957, 180: 981-982

2 Møller CK. Crystal structure and photoconductivity of cæsium plumbohalides. Nature, 1958, 182: 1436-1436

3 Kim HS, Lee CR, Im JH, et al. Lead iodide perovskite sensitized all-solid-state submicron thin film mesoscopic solar cell with efficiency exceeding 9\%. Sci Rep, 2012, 2: 591

4 Noh JH, Im SH, Heo JH, et al. Chemical management for colorful, efficient, and stable inorganic-organic hybrid nanostructured solar cells. Nano Lett, 2013, 13: 1764-1769

5 Zheng K, Zhu Q, Abdellah M, et al. Exciton binding energy and the nature of emissive states in organometal halide perovskites. J Phys Chem Lett, 2015, 6: 2969-2975

6 Stranks SD, Eperon GE, Grancini G, et al. Electron-hole diffusion lengths exceeding 1 micrometer in an organometal trihalide perovskite absorber. Science, 2013, 342: 341-344

7 Xing G, Mathews N, Sun S, et al. Long-range balanced electronand hole-transport lengths in organic-inorganic $\mathrm{CH}_{3} \mathrm{NH}_{3} \mathrm{PbI}_{3}$. Science, 2013, 342: 344-347
8 Leijtens T, Stranks SD, Eperon GE, et al. Electronic properties of meso-superstructured and planar organometal halide perovskite films: charge trapping, photodoping, and carrier mobility. ACS Nano, 2014, 8: 7147-7155

9 Chen Y, Peng J, Su D, et al. Efficient and balanced charge transport revealed in planar perovskite solar cells. ACS Appl Mater Interfaces, 2015, 7: 4471-4475

10 Wehrenfennig C, Eperon GE, Johnston MB, et al. High charge carrier mobilities and lifetimes in organolead trihalide perovskites. Adv Mater, 2014, 26: 1584-1589

11 Niu G, Li W, Li J, et al. Progress of interface engineering in perovskite solar cells. Sci China Mater, 2016, 59: 728-742

12 Wei J, Shi C, Zhao Y, et al. Potentials and challenges towards application of perovskite solar cells. Sci China Mater, 2016, 59: 769-778

13 Kojima A, Teshima K, Shirai Y, et al. Organometal halide perovskites as visible-light sensitizers for photovoltaic cells. J Am Chem Soc, 2009, 131: 6050-6051

14 http://www.nrel.gov/ncpv/images/efficiency_chart.jpg

15 Tan ZK, Moghaddam RS, Lai ML, et al. Bright light-emitting diodes based on organometal halide perovskite. Nat Nanotech, 2014, 9: 687-692

16 Xing G, Mathews N, Lim SS, et al. Low-temperature solution-processed wavelength-tunable perovskites for lasing. Nat Mater, 2014, 13: 476-480

17 Guo Y, Liu C, Tanaka H, et al. Air-stable and solution-processable perovskite photodetectors for solar-blind UV and visible light. J Phys Chem Lett, 2015, 6: 535-539

18 Da P, Cha M, Sun L, et al. High-performance perovskite photoanode enabled by Ni passivation and catalysis. Nano Lett, 2015, 15: 3452-3457

19 He Y, Galli G. Perovskites for solar thermoelectric applications: a first principle study of $\mathrm{CH}_{3} \mathrm{NH}_{3} \mathrm{AI}_{3}(\mathrm{~A}=\mathrm{Pb}$ and $\mathrm{Sn})$. Chem Mater, 2014, 26: 5394-5400

20 Snaith HJ. Perovskites: the emergence of a new era for low-cost, high-efficiency solar cells. J Phys Chem Lett, 2013, 4: 3623-3630

21 Baeg KJ, Binda M, Natali D, et al. Organic light detectors: photodiodes and phototransistors. Adv Mater, 2013, 25: 4267-4295

22 Park NG. Perovskite solar cells: an emerging photovoltaic technology. Mater Today, 2015, 18: 65-72

23 Kazim S, Nazeeruddin MK, Grätzel M, et al. Perovskite as light harvester: a game changer in photovoltaics. Angew Chem Int Ed, 2014, 53: 2812-2824

24 Boix PP, Nonomura K, Mathews N, et al. Current progress and future perspectives for organic/inorganic perovskite solar cells. Mater Today, 2014, 17: 16-23

25 Green MA, Ho-Baillie A, Snaith HJ. The emergence of perovskite solar cells. Nat Photon, 2014, 8: 506-514

26 Sum TC, Mathews N. Advancements in perovskite solar cells: photophysics behind the photovoltaics. Energ Environ Sci, 2014, 7: 2518-2534

27 Kim HS, Im SH, Park NG. Organolead halide perovskite: new horizons in solar cell research. J Phys Chem C, 2014, 118: 5615-5625

28 Jung HS, Park NG. Perovskite solar cells: from materials to devices. Small, 2015, 11: 10-25

29 Stranks SD, Snaith HJ. Metal-halide perovskites for photovoltaic and light-emitting devices. Nat Nanotech, 2015, 10: 391-402

30 Fan R, Huang Y, Wang L, et al. The progress of interface design in perovskite-based solar cells. Adv Energ Mater, 2016, 6: 1600460

31 Veldhuis SA, Boix PP, Yantara N, et al. Perovskite materials for light-emitting diodes and lasers. Adv Mater, 2016, 28: 6804-6834

32 Tong X, Lin F, Wu J, et al. High performance perovskite solar cells. Adv Sci, 2016, 3: 1500201 
33 Chen Y, He M, Peng J, et al. Structure and growth control of organic-inorganic halide perovskites for optoelectronics: from polycrystalline films to single crystals. Adv Sci, 2016, 3: 1500392

34 Correa-Baena JP, Abate A, Saliba M, et al. The rapid evolution of highly efficient perovskite solar cells. Energ Environ Sci, 2017, 10: 710-727

35 Wang Z, Shi Z, Li T, et al. Stability of perovskite solar cells: a prospective on the substitution of the A cation and $\mathrm{X}$ anion. Angew Chem Int Ed, 2017, 56: 1190-1212

36 Shi D, Adinolfi V, Comin R, et al. Low trap-state density and long carrier diffusion in organolead trihalide perovskite single crystals. Science, 2015, 347: 519-522

37 Dong Q, Fang Y, Shao Y, et al. Electron-hole diffusion lengths > 175 $\mathrm{m}$ in solution-grown $\mathrm{CH}_{3} \mathrm{NH}_{3} \mathrm{PbI}_{3}$ single crystals. Science, 2015 , 347: 967-970

38 Weber $\mathrm{D}$. $\mathrm{CH}_{3} \mathrm{NH}_{3} \mathrm{PbX}_{3}$, ein $\mathrm{Pb}(\mathrm{II})$-system mit kubischer perowskitstruktur / $\mathrm{CH}_{3} \mathrm{NH}_{3} \mathrm{PbX}_{3}$, a $\mathrm{Pb}(\mathrm{II})$-system with cubic perovskite structure. Z für Naturforschung B, 1978, 33

39 Weber D. $\mathrm{CH}_{3} \mathrm{NH}_{3} \mathrm{SnBr}_{x} \mathrm{I}_{3-x}(x=0-3)$, ein $\mathrm{Sn}(\mathrm{II})$-system mit kubis cher perowskitstruktur/ $\mathrm{CH}_{3} \mathrm{NH}_{3} \mathrm{SnBr}_{x} \mathrm{I}_{3-x}(x=0-3)$, a $\mathrm{Sn}$ (II)-system with cubic perovskite structure. Z für Naturforschung B, 1978, 33

40 Stoumpos CC, Malliakas CD, Kanatzidis MG. Semiconducting tin and lead iodide perovskites with organic cations: phase transitions, high mobilities, and near-infrared photoluminescent properties. Inorg Chem, 2013, 52: 9019-9038

41 Baikie T, Fang Y, Kadro JM, et al. Synthesis and crystal chemistry of the hybrid perovskite $\left(\mathrm{CH}_{3} \mathrm{NH}_{3}\right) \mathrm{PbI}_{3}$ for solid-state sensitised solar cell applications. J Mater Chem A, 2013, 1: 5628

42 Dang Y, Liu Y, Sun Y, et al. Bulk crystal growth of hybrid perovskite material $\mathrm{CH}_{3} \mathrm{NH}_{3} \mathrm{PbI}_{3}$. CrystEngComm, 2015, 17: 665-670

43 Poglitsch A, Weber D. Dynamic disorder in methylammoniumtrihalogenoplumbates (II) observed by millimeter-wave spectroscopy. J Chem Phys, 1987, 87: 6373-6378

44 Lian Z, Yan Q, Lv Q, et al. High-performance planar-type photodetector on (100) facet of $\mathrm{MAPbI}_{3}$ single crystal. Sci Rep, 2015 5: 16563

45 Fang Y, Dong Q, Shao Y, et al. Highly narrowband perovskite single-crystal photodetectors enabled by surface-charge recombination. Nat Photon, 2015, 9: 679-686

$46 \mathrm{Su}$ J, Chen DP, Lin CT. Growth of large $\mathrm{CH}_{3} \mathrm{NH}_{3} \mathrm{PbX}_{3}(\mathrm{X}=\mathrm{I}, \mathrm{Br})$ single crystals in solution. J Cryst Growth, 2015, 422: 75-79

47 Dang Y, Zhou Y, Liu X, et al. Formation of hybrid perovskite tin iodide single crystals by top-seeded solution growth. Angew Chem, 2016, 128: 3508-3511

48 Dang Y, Zhong C, Zhang G, et al. Crystallographic investigations into properties of acentric hybrid perovskite single crystals $\mathrm{NH}\left(\mathrm{CH}_{3}\right)_{3} \mathrm{SnX}_{3}(\mathrm{X}=\mathrm{Cl}, \mathrm{Br})$. Chem Mater, 2016, 28: 6968-6974

49 Lian Z, Yan Q, Gao T, et al. Perovskite $\mathrm{CH}_{3} \mathrm{NH}_{3} \mathrm{PbI}_{3}(\mathrm{Cl})$ single crystals: rapid solution growth, unparalleled crystalline quality, and low trap density toward $10^{8} \mathrm{~cm}^{-3}$. J Am Chem Soc, 2016, 138: 9409-9412

50 Saidaminov MI, Abdelhady AL, Murali B, et al. High-quality bulk hybrid perovskite single crystals within minutes by inverse temperature crystallization. Nat Commun, 2015, 6: 7586-7592

51 Saidaminov MI, Abdelhady AL, Maculan G, et al. Retrograde solubility of formamidinium and methylammonium lead halide perovskites enabling rapid single crystal growth. Chem Commun, 2015, 51: 17658-17661

52 Maculan G, Sheikh AD, Abdelhady AL, et al. $\mathrm{CH}_{3} \mathrm{NH}_{3} \mathrm{PbCl}_{3}$ single crystals: inverse temperature crystallization and visible-blind UV-photodetector. J Phys Chem Lett, 2015, 6: 3781-3786

53 Zhumekenov AA, Saidaminov MI, Haque MA, et al. Formami- dinium lead halide perovskite crystals with unprecedented long carrier dynamics and diffusion length. ACS Energ Lett, 2016, 1: $32-37$

54 Abdelhady AL, Saidaminov MI, Murali B, et al. Heterovalent dopant incorporation for bandgap and type engineering of perovskite crystals. J Phys Chem Lett, 2016, 7: 295-301

55 Han Q, Bae SH, Sun P, et al. Single crystal formamidinium lead iodide $\left(\mathrm{FAPbI}_{3}\right)$ : insight into the structural, optical, and electrical properties. Adv Mater, 2016, 28: 2253-2258

56 Kadro JM, Nonomura K, Gachet D, et al. Facile route to freestanding $\mathrm{CH}_{3} \mathrm{NH}_{3} \mathrm{PbI}_{3}$ crystals using inverse solubility. Sci Rep, 2015, 5: 11654

57 Zhang T, Yang M, Benson EE, et al. A facile solvothermal growth of single crystal mixed halide perovskite $\mathrm{CH}_{3} \mathrm{NH}_{3} \mathrm{~Pb}\left(\mathrm{Br}_{1-x} \mathrm{Cl}_{x}\right)_{3}$. Chem Commun, 2015, 51: 7820-7823

58 Liu Y, Yang Z, Cui D, et al. Two-inch-sized perovskite $\mathrm{CH}_{3} \mathrm{NH}_{3} \mathrm{PbX}_{3}(\mathrm{X}=\mathrm{Cl}, \mathrm{Br}, \mathrm{I})$ crystals: growth and characterization. Adv Mater, 2015, 27: 5176-5183

59 Liu Y, Sun J, Yang Z, et al. 20-mm-Large single-crystalline formamidinium-perovskite wafer for mass production of integrated photodetectors. Adv Optical Mater, 2016, 4: 1829-1837

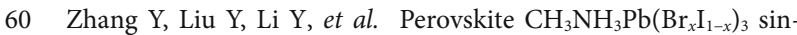
gle crystals with controlled composition for fine-tuned bandgap towards optimized optoelectronic applications. J Mater Chem C, 2016, 4: 9172-9178

61 Dirin DN, Cherniukh I, Yakunin S, et al. Solution-grown CsPbBr perovskite single crystals for photon detection. Chem Mater, 2016, 28: $8470-8474$

62 Rakita Y, Kedem N, Gupta S, et al. Low-temperature solutiongrown $\mathrm{CsPbBr}_{3}$ single crystals and their characterization. Cryst Growth Des, 2016, 16: 5717-5725

63 Yang Y, Yan Y, Yang M, et al. Low surface recombination velocity in solution-grown $\mathrm{CH}_{3} \mathrm{NH}_{3} \mathrm{PbBr}_{3}$ perovskite single crystal. Nat Commun, 2015, 6: 7961-7967

64 Zhou H, Nie Z, Yin J, et al. Antisolvent diffusion-induced growth, equilibrium behaviours in aqueous solution and optical properties of $\mathrm{CH}_{3} \mathrm{NH}_{3} \mathrm{PbI}_{3}$ single crystals for photovoltaic applications. RSC Adv, 2015, 5: 85344-85349

65 Kobayashi M, Omata K, Sugimoto S, et al. Scintillation characteristics of $\mathrm{CsPCl}_{3}$ single crystals. Nucl Instruments Methods Phys Res Sect A-Accelerators Spectrometers Detectors Associated Equipment, 2008, 592: 369-373

66 Stoumpos CC, Malliakas CD, Peters JA, et al. Crystal growth of the perovskite semiconductor $\mathrm{CsPBr}_{3}$ : a new material for high-energy radiation detection. Cryst Growth Des, 2013, 13: 2722-2727

67 Peng W, Wang L, Murali B, et al. Solution-grown monocrystalline hybrid perovskite films for hole-transporter-free solar cells. Adv Mater, 2016, 28: 3383-3390

68 Liu Y, Zhang Y, Yang Z, et al. Thinness- and shape-controlled growth for ultrathin single-crystalline perovskite wafers for mass production of superior photoelectronic devices. Adv Mater, 2016, 28: 9204-9209

69 Chen YX, Ge QQ, Shi Y, et al. General space-confined on-substrate fabrication of thickness-adjustable hybrid perovskite single-crystalline thin films. J Am Chem Soc, 2016, 138: 16196-16199

70 Rao HS, Li WG, Chen BX, et al. In situ growth of $120 \mathrm{~cm}^{2}$ $\mathrm{CH}_{3} \mathrm{NH}_{3} \mathrm{PbBr}_{3}$ perovskite crystal film on FTO glass for narrowband-photodetectors. Adv Mater, 2017, 29: 1602639

71 Zhao $\mathrm{P}, \mathrm{Xu}$ J, Dong X, et al. Large-size $\mathrm{CH}_{3} \mathrm{NH}_{3} \mathrm{PbBr}_{3}$ single crystal: growth and in situ characterization of the photophysics properties. J Phys Chem Lett, 2015, 6: 2622-2628

72 Fang HH, Raissa R, Abdu-Aguye M, et al. Photophysics of organic- 
inorganic hybrid lead iodide perovskite single crystals. Adv Funct Mater, 2015, 25: 2378-2385

73 Yang D, Xie C, Sun J, et al. Amplified spontaneous emission from organic-inorganic hybrid lead iodide perovskite single crystals under direct multiphoton excitation. Adv Optical Mater, 2016, 4: 1053-1059

74 Valverde-Chávez DA, Ponseca CS, Stoumpos CC, et al. Intrinsic femtosecond charge generation dynamics in single crystal $\mathrm{CH}_{3} \mathrm{NH}_{3} \mathrm{PbI}_{3}$. Energ Environ Sci, 2015, 8: 3700-3707

75 Fang Y, Wei H, Dong Q, et al. Quantification of re-absorption and re-emission processes to determine photon recycling efficiency in perovskite single crystals. Nat Commun, 2017, 8: 14417

$76 \mathrm{Lv} \mathrm{Q}, \mathrm{He} \mathrm{W}$, Lian Z, et al. Anisotropic moisture erosion of $\mathrm{CH}_{3} \mathrm{NH}_{3} \mathrm{PbI}_{3}$ single crystals. CrystEngComm, 2017, 19: 901-904

77 Grattan KTV, Sun T. Fiber optic sensor technology: an overview. Sensors Actuators A-Phys, 2000, 82: 40-61

78 Ghezzi D, Antognazza MR, Dal Maschio M, et al. A hybrid bioorganic interface for neuronal photoactivation. Nat Commun, 2011, 2: $166-173$

79 Razeghi M, Rogalski A. Semiconductor ultraviolet detectors. J Appl Phys, 1996, 79: 7433-7473

80 Chen G, Liang B, Liu X, et al. High-performance hybrid phenyl- $\mathrm{C}_{61}$-butyric acid methyl ester/ $\mathrm{Cd}_{3} \mathrm{P}_{2}$ nanowire ultraviolet-visible-near infrared photodetectors. ACS Nano, 2014, 8: 787-796

81 Fang H, Li Q, Ding J, et al. A self-powered organolead halide perovskite single crystal photodetector driven by a DVD-based triboelectric nanogenerator. J Mater Chem C, 2016, 4: 630-636

82 Ding J, Fang H, Lian Z, et al. A self-powered photodetector based on a $\mathrm{CH}_{3} \mathrm{NH}_{3} \mathrm{PbI}_{3}$ single crystal with asymmetric electrodes. CrystEngComm, 2016, 18: 4405-4411

83 Shaikh PA, Shi D, Retamal JRD, et al. Schottky junctions on perovskite single crystals: light-modulated dielectric constant and self-biased photodetection. J Mater Chem C, 2016, 4: 8304-8312

84 Cao M, Tian J, Cai Z, et al. Perovskite heterojunction based on $\mathrm{CH}_{3} \mathrm{NH}_{3} \mathrm{PbBr}_{3}$ single crystal for high-sensitive self-powered photodetector. Appl Phys Lett, 2016, 109: 233303

85 Dong Q, Song J, Fang Y, et al. Lateral-structure single-crystal hybrid perovskite solar cells via piezoelectric poling. Adv Mater, 2016, 28: 2816-2821

86 Kasap S, Frey JB, Belev G, et al. Amorphous and polycrystalline photoconductors for direct conversion flat panel X-ray image sensors. Sensors, 2011, 11: 5112-5157

87 Yaffe MJ, Rowlands JA. X-ray detectors for digital radiography. Phys Med Biol, 1997, 42: 1-39

88 Tegze M, Faigel G. X-ray holography with atomic resolution. Nature, 1996, 380: 49-51

89 Evans RD, Noyau A. The Atomic Nucleus. Summit: McGraw-Hill, 1955, 582

90 Heiss W, Brabec C. X-ray imaging: perovskites target X-ray detection. Nat Photon, 2016, 10: 288-289

91 Yakunin S, Sytnyk M, Kriegner D, et al. Detection of X-ray photons by solution-processed lead halide perovskites. Nat Photon, 2015, 9: 444-449

92 Náfrádi B, Náfrádi G, Forró L, et al. Methylammonium lead iodide for efficient X-ray energy conversion. J Phys Chem C, 2015, 119: 25204-25208

93 Wei H, Fang Y, Mulligan P, et al. Sensitive X-ray detectors made of methylammonium lead tribromide perovskite single crystals. Nat Photon, 2016, 10: 333-339

94 Yakunin S, Dirin DN, Shynkarenko Y, et al. Detection of gamma photons using solution-grown single crystals of hybrid lead halide perovskites. Nat Photon, 2016, 10: 585-589

Acknowledgments This work was supported by the National Natural Science Foundation of China (91333109 and 21671115); Tsinghua University Initiative Scientific Research Program (20131089202 and 20161080165) and the Open Research Fund Program of the State Key Laboratory of Low-Dimensional Quantum Physics (KF201516) are also acknowledged for partial financial support.

Author contributions Yan Q conceived the work. Ding J and Yan Q wrote the manuscript.

Conflict of interest The authors declare that they have no conflict of interest. 


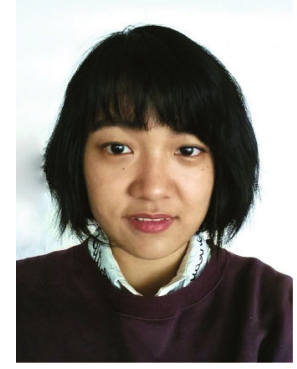

Jie Ding received a BSc degree in chemistry (2014) from Beijing University of Chemical Technology. After that, she has been pursuing her PhD degree at Tsinghua University. Her research interests focus on the hybrid perovskite single crystal growth and application.

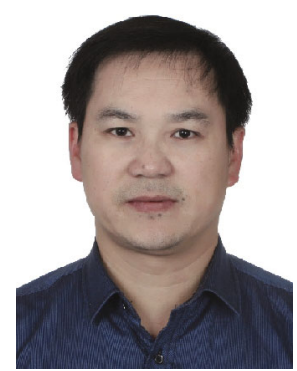

Qingfeng Yan earned his PhD degree from the Institute of Semiconductors, Chinese Academy of Sciences in 2003. He joined the Department of Chemical \& Biomolecular Engineering, National University of Singapore as a research fellow in August 2003. From April 2006, he worked with the School of Materials Science and Engineering, Nanyang Technological University, Singapore and the Department of Materials Science and Engineering, Massachusetts Institute of Technology, USA as a joint postdoctoral fellow. Dr. Yan joined the Department of Chemistry, Tsinghua University as an associate professor in 2008. His current research interest focuses on the synthesis of functional crystals and materials chemistry.

\section{有机-无机杂化钙钛矿单晶研究进展: 生长技术及应用}

丁洁, 严清峰*

摘要 作为一种新型的光电材料, 有机-无机杂化钙钛矿以其高光吸收系数、长扩散长度、高载流子迁移率等优点为人们所关注. 这类材料 在太阳电池、光电探测器、发光二极管、激光器、催化等诸多领域有极为优秀的表现. 与多晶材料相比, 单晶的低缺陷、无晶界等特点 使其拥有更好的性能. 本文从生长技术和应用两个方面综述了有机-无机杂化钙铁矿单晶的研究进展, 并对该领域的未来发展进行了展望. 